NBER WORKING PAPER SERIES

\title{
35 YEARS OF REFORMS: \\ A PANEL ANALYSIS OF THE INCIDENCE OF, AND EMPLOYEE AND EMPLOYER RESPONSES TO, SOCIAL SECURITY CONTRIBUTIONS
}

\author{
Stuart Adam \\ David Phillips \\ Barra Roantree \\ Working Paper 23336 \\ http://www.nber.org/papers/w23336 \\ NATIONAL BUREAU OF ECONOMIC RESEARCH \\ 1050 Massachusetts Avenue \\ Cambridge, MA 02138 \\ April 2017
}

The authors thank Richard Blundell, Raj Chetty, Carl Emmerson, Jon Gruber, Henrik Kleven, Thomas Le Barbanchon, Emmanuel Saez, Andrea Weber and seminar participants at the IFS and the 2016 Trans-Atlantic Public Economics Seminar for helpful comments. We especially thank colleagues at DIW Berlin, CPB Netherlands and IPP Paris School of Economics, working with us on the broader project on 'The impact of social security contributions on earnings' of which this paper is a part, for many helpful discussions throughout the course of the project. All errors and omissions are the responsibility of the authors. We gratefully acknowledge funding from ESRC Research Grant ES/K006185/1, the European Research Council (reference ERC-2010AdG-269440-WSCWTBDS) and the ESRC Centre for the Microeconomic Analysis of Public Policy based at the Institute for Fiscal Studies (ES/M010147/1). Data from the New Earnings Survey Panel Dataset is produced by the Office for National Statistics and supplied by the Secure Data Service at the UK Data Archive. The views expressed herein are those of the authors and do not necessarily reflect the views of the National Bureau of Economic Research.

NBER working papers are circulated for discussion and comment purposes. They have not been peer-reviewed or been subject to the review by the NBER Board of Directors that accompanies official NBER publications.

(C) 2017 by Stuart Adam, David Phillips, and Barra Roantree. All rights reserved. Short sections of text, not to exceed two paragraphs, may be quoted without explicit permission provided that full credit, including $\odot$ notice, is given to the source. 
35 Years of Reforms: A Panel Analysis of the Incidence of, and Employee and Employer

Responses to, Social Security Contributions in the UK

Stuart Adam, David Phillips, and Barra Roantree

NBER Working Paper No. 23336

April 2017

JEL No. H2,J2,J3

\section{ABSTRACT}

We exploit variation in National Insurance contributions (NICs) - the UK's system of social security contributions - and a large panel dataset to examine the effects of 35 years of employee and employer NICs reforms on labour cost (gross earnings plus employer NICs), hours of work and labour cost per hour, both immediately (0-6 months) after reforms are implemented and in the slightly longer term (12-18 months). We consider assumptions under which the estimated coefficients on net-of-marginal and net-of-average tax rates in a panel regression can be interpreted as behavioural elasticities or as reflecting incidence. We find a compensated elasticity of taxable earnings with respect to the marginal rate of employee NICs of about 0.2-0.3, operating largely through hours of work, while that with respect to the marginal rate of employer NICs is not statistically significantly different from zero. We also find that labour cost falls by a much larger amount when the average rate of employer NICs is reduced than when the average rate of employee NICs is reduced, which is consistent with the economic incidence of NICs being strongly affected by its formal legal incidence. Estimates from the hours and hourly labour cost regressions provide further support to this interpretation of the findings, and also suggest the presence of substantial income effects - though also, after 1999, a puzzling effect of average employer NICs rates on hours of work. Each of these results remains true after 12-18 months (if anything, coefficients on lagged changes in NICs rates strengthen these findings), implying that any shifting of employer NICs changes to the individual employees concerned (and vice versa for employee NICs) does not begin over this time horizon. These results are similar to those found by Lehmann et al. (2013) for France but represent an extension of that work by considering hours as well as labour cost responses and second-year as well as immediate effects.

Stuart Adam

Institute for Fiscal Studies

7 Ridgmount Street

London WC1E 7AE

United Kingdom

stuart.adam@ifs.org.uk

David Phillips

Institute for Fiscal Studies

7 Ridgmount Street

London WC1E 7AE

United Kingdom

david_p@ifs.org.uk
Barra Roantree

Institute for Fiscal Studies

7 Ridgmount Street

London WC1E 7AE

United Kingdom

barra_r@ifs.org.uk 


\section{Introduction}

Social security contributions (SSCs) such as the UK's National Insurance contributions (NICs) are a large part of the labour tax wedge. According to the OECD, the average labour tax wedge for the average worker was $35.9 \%$ in 2015, of which 21.1 percentage points related to SSCs. ${ }^{2}$ In the UK, NICs accounted for 16.7 percentage points of the overall $30.8 \%$ labour tax wedge for someone with average earnings. There is therefore good reason to investigate both the behavioural effects of SSCs and their economic incidence.

Unlike the income tax due on labour income, which is levied on the employee only, SSCs are levied on both employees and employers. In the UK, for instance, employee NICs are currently levied at a rate of $12 \%$, and employer NICs $13.8 \%$, of gross earnings above an exemption threshold (falling to $2 \%$ above a higher threshold for employees). Standard models of the labour market predict identical responses and economic incidence for employee and employer SSCs, at least in the long run. The effects of a tax on the amount of labour utilised and the amount paid by employers and received by employees reflects the relative elasticities of labour demand and supply (or the bargaining power of employees versus employers), not the formal legal incidence of the tax. ${ }^{3}$ If bargaining and contracting relates to gross earnings, however, as is typically the case, nominal gross earnings may be 'sticky', meaning legal incidence may affect economic incidence, at least in the short term.

Empirical evidence on this matter is relatively limited. Much of the New Tax Responsiveness (NTR) literature on the response of income or earnings to taxation focuses on income tax rather than SSCs (see Saez et al (2012) for a review), providing surprisingly scant evidence on the effects of SSCs specifically, and much of that literature implicitly assumes that taxes are fully incident on the individual taxpayer. The literature on the incidence and employment effects of SSCs, meanwhile, tends to focus on responses to changes in employer or combined rates, perhaps reflecting the fact that independent variation in employee and employer rates is difficult to come by.

A series of reforms to the UK's system of NICs in the 1980s, 1990s and (to a lesser extent) 2000s does provide such independent variation. In this paper we use a panel regression approach to exploit this variation, using data from the New Earnings Survey Panel Dataset (NESPD) - which includes accurate panel data on the earnings and hours of a large, randomly selected sample of workers for up to 35 years - to examine the effects of employee and employer NICs on labour cost (gross earnings plus employer NICs), hours of work, and labour cost per hour. Data with this combination of large sample size, accurate measurement of earnings, long historical coverage and a panel

\footnotetext{
${ }^{2}$ This is the average labour tax rate for a single adult with no children and $100 \%$ of mean earnings. https://stats.oecd.org/Index.aspx?DataSetCode=AWCOMP.

${ }^{3}$ This is true of standard versions of the competitive, union bargaining, search and matching, and efficiency wage models, as set out in Pissarides (1998).
} 
dimension have never previously been used in the UK - and rarely in other countries to examine such questions. In doing this we set out a series of assumptions that one can make in order to interpret the estimated coefficients on net-of-marginal and net-ofaverage tax rates as behavioural elasticities or as reflecting the incidence of the tax.

Our work builds on that of Lehmann et al (2013), who undertake a similar analysis of reforms to employer SSCs and income tax credits in France in the mid-2000s. They find evidence of compensated behavioural responses to income tax but not employer SSCs, and that economic incidence of taxes is affected by formal incidence, at least in the year following a reform. Our work differs from theirs in that we focus on comparing employee and employer NICs, which (unlike SSCs and income tax in France) do not have differ significantly in terms of the linkages between liabilities and entitlements to pensions and unemployment or disability assistance (and indeed, the link between contributions and entitlements is weak at the margin in the UK). We extend their work by considering not only responses of labour cost but also hours of work and labour cost per hour. This provides additional evidence that the results we obtain - which are similar to Lehmann et al - reflect differential incidence of the taxes, rather than differential income effects, for instance. In addition, as well as looking at very short-run responses (0-6 months), we look at slightly longer run responses (12-18 months) by including lagged changes in net-of-NICs rates as independent variables in our regressions.

In order to say something about both behavioural responses to NICs and the incidence of NICs, assumptions about the nature of behavioural responses need to be made. Our first approach directly follows that of Lehmann et al, and utilises information on labour costs (constructed from the observed earnings in our data) only. Motivated by the NTR literature, which emphasises responses to taxes other than hours of work, this approach allows for NICs to affect hourly wages via behavioural responses such as effort or avoidance (rather than via the effects of tax-incidence shifting). Responses of labour cost to changes in marginal NICs rates reflect substitution effects on both hours and non-hours margins. Responses of weekly or monthly earnings to changes in average tax rates can be interpreted as income effects (if the incidence of the tax is assumed) or else as reflecting the incidence of NICs (if we assume no income effects). Our second approach utilises data on hours of work and assumes that behavioural responses take the form of changes in hours of work while any changes in hourly labour cost reflect the incidence of NICs. In effect, this means ruling out the non-hours responses which, in part, motivated the NTR literature.

Estimates from our labour cost regressions are similar to those of Lehmann et al (2013). The compensated elasticity with respect to the net-of-marginal employee NICs rate is statistically significant and positive (around $0.2-0.3$ ), while that with respect to the netof-marginal employer NICs rate is not statistically significantly different from zero. The coefficient on the net-of-average employee NICs rate is much smaller, in absolute magnitude, than the coefficient on the net-of-average employer NICs rate, which is large 
and negative. This is consistent with the economic incidence of NICs following its formal legal incidence. Estimates from the hours and hourly labour costs regressions provide further support to this interpretation of the findings, and also suggest substantial income effects. Each of these results remains true after 12-18 months following a reform (if anything, the effects of lagged changes in NICs rates is to reinforce initial effects), implying that any shifting of employer NICs changes to the individual employees concerned (and vice versa for employee NICs) does not begin over this time horizon.

Like Lehmann et al (2013), and much of the micro-econometric literature on labour tax incidence, we use 'incident on employers' as a shorthand to mean 'incident on someone other than the employee whose tax rate changed'. Of course, the ultimate burden of a tax must always fall on real people, not the businesses or organisations employing them; it may be passed on to the employers' owners, customers and/or suppliers, and thence perhaps more widely via general equilibrium responses. One important possibility is that a tax that is not incident on the employee whose tax rate changes may nevertheless be incident on a broader group of workers: the nature of market responses may be such that (say) a tax increase affecting one small group of employees results not in a large wage reduction for those employees but in a small wage reduction for all employees in the firm, or in an infinitesimal reduction in equilibrium wages in the wider market. All we attempt to discern in this paper is how an individual's wage is affected by the tax rate applied to that individual's earnings; insofar as their net wage is not reduced one-for-one then we refer to the tax as being at least partly incident 'on the employer', even though the burden may be felt by a wider group of employees rather than by (say) the employer's shareholders.

The paper proceeds as follows. In Section 2 we describe the UK's NICs regime and the reforms that we use to identify its effects. Section 3 briefly reviews the relevant NTR and incidence literatures. Section 4 sets out the conceptual underpinnings of our analysis, focusing on the identification of the behavioural and incidence effects of NICs and other labour taxes. Section 5 describes the empirical specification, focusing on our strategy for addressing the endogeneity of changes in NICs rates and on our use of lagged changes in NICs rates to examine slightly longer-run effects on labour cost and hours of work. Section 6 describes our data source, the NESPD, and our results are set out in Section 7. Section 8 concludes.

\section{Institutional background}

Like SSC systems in most countries, the UK's system of NICs consists of both employer and employee contributions. Contributions are a function of the employee's gross earnings (including employee, but not employer, private pension contributions) and are calculated separately in each pay period (typically a week or month): unlike income tax, NICs liability over the course of a year does not depend on earnings for the year as a 
whole. The NICs rate schedule changed markedly during the period we analyse (1978 to 2015), and it is those changes that we exploit in this paper.

Figure 1 shows the structure of the combined employee and employer NI system before and after the important 1985 reform and as it stood after the end of our period of analysis, in 2015-16. To facilitate comparison, thresholds from earlier systems have been uprated to April 2015 prices.

\section{Figure 1. The changing structure of National Insurance contributions (April 2015 prices)}

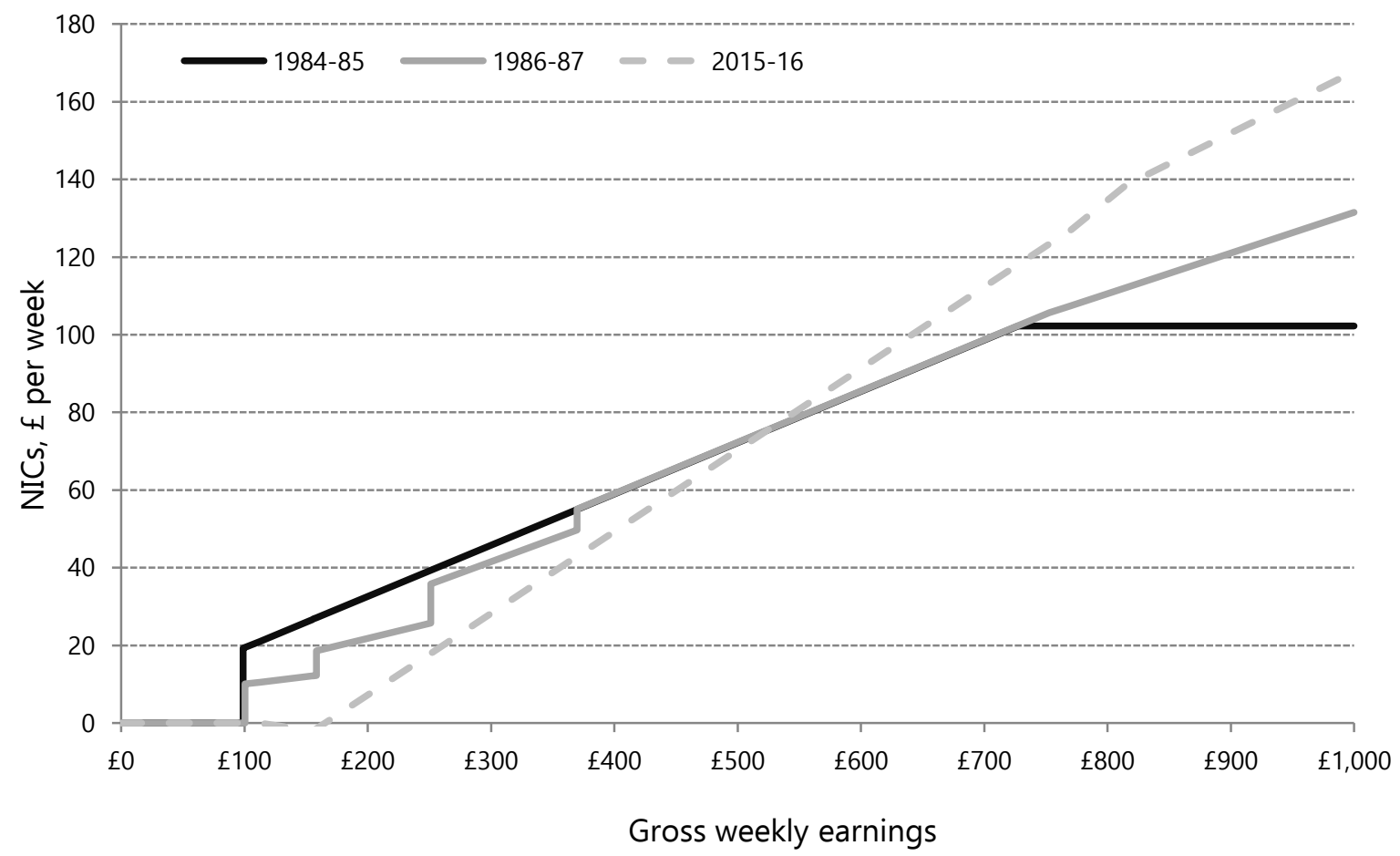

Note: Cash values uprated to April 2015 prices using the retail prices index. 1984-85 schedule is that applying from October 1984. Assumes employee contracted out of the State Earnings-Related Pension Scheme (SERPS) or State Second Pension (S2P) into a defined-benefit private pension scheme.

No NICs are due below an exemption threshold. ${ }^{4}$ Before 1985, contributions for those earning above this level were charged at a flat percentage rate on the entirety of earnings, including earnings below the threshold, up to a ceiling called the Upper Earnings Limit (UEL). This meant a jump, or notch, in contributions at the threshold: both marginal and average rates of NICs increased from zero to the headline rates, which at the start of 1985 stood at $9 \%$ for employees and $10.45 \%$ for employers. The October 1985 reform replaced this single large notch and flat rate of tax with a series of smaller notches, reducing the jump in marginal and average rates at the exemption threshold to 5\% each for employees and employers, and introducing a number of graduated steps instead, where higher (marginal and average) rates applied to the entirety of earnings once earnings exceeded higher thresholds. For employees, two

\footnotetext{
${ }^{4}$ This threshold was formerly the Lower Earnings Limit, now the Earnings Threshold.
} 
additional notches were introduced at higher thresholds, so that the rates of employee NICs jumped to $7 \%$ and then $9 \%$, with the highest rate applying to all earnings up to the UEL. For employers three additional notches were introduced at higher thresholds (at rates of $7 \%, 9 \%$ and $10.45 \%$ ). At the same time, the cap on employer contributions was abolished so that the highest rate of employer NICs applied even above the UEL. The effect of this reform on the combined employee and employer NICs schedule can be seen in the black and solid grey lines in Figure 1.

The system of graduated steps did not last. In October 1989, the system of graduated employee contributions was replaced by a single small notch at the threshold (equivalent to $2 \%$ of the threshold) and a single $9 \%$ rate of employee NICs that applied to earnings between the threshold and the UEL. However, the graduated system of employer NICs with four notches remained in place at that stage. In April 1999 the remaining notch in the employee NICs schedule, and all of the notches in the employer schedule, were removed, so that the schedule now contains only kinks (that is, changes in marginal contribution rates).

In addition to these main structural reforms, there were many (mostly small) changes in NICs rates and thresholds throughout the period we analyse, culminating in the light grey line in Figure 1. Among these changes, a one percentage point increase in both employee and employer NICs introduced in 2003 is notable as, for the first time, the increase in employee rates applied above as well as below the UEL, so that the UEL already abolished for employer contributions in 1985 - no longer acted as a complete cap on employee contributions either. Table 1 shows the rates and thresholds that applied in each year.

All these changes contribute to the variation that provides econometric identification in our model. The combination of changes in both thresholds and rates, the move from a notch-based system to a kink-based system via a series of smaller notches, and the extension of NICs (particularly employer NICs) above the UEL, gives us a range of sources of variation across the earnings distribution. Sometimes employer and employee NICs rates changed together, but sometimes not; in some cases individuals' marginal and average NICs rates changed in parallel, but sometimes differentially. This allows us to separately identify earnings responses to changes in both marginal and average rates of both employee and employer NICs.

National Insurance was originally envisaged as a 'true' social insurance scheme, with a broadly actuarial link between contributions paid and benefit entitlements for each individual. Insofar as there is - or, perhaps, is perceived to be - such a link, National Insurance may not have the same disincentive effects as a simple tax on earnings (Summers, 1989). Increasing earnings is made less attractive by the NICs that must be paid on the additional earnings, but simultaneously made more attractive by the increased entitlements it generates; the extent to which these offset each other depends on how much I value the increased entitlements. However, the link between 
contributions and benefits - particularly at the margin - had already been significantly weakened by 1978 , and had all but disappeared by 2015.5

There was one strongly contributory element to the National Insurance scheme. Until very recently, individuals contributing to a private pension could choose whether to 'contract in' or 'contract out' of the second pillar of the UK state pension system (initially the State Earnings-Related Pension Scheme, SERPS, and later the State Second Pension, S2P). Those contracting out were charged slightly lower rates of employee and employer NICS on earnings between a lower threshold (the Lower Earnings Limit, LEL) and an upper threshold (the UEL or, since 2009, the Upper Accruals Point) in exchange for sacrificing future entitlement to SERPS/S2P. ${ }^{6}$ For those contributing to a definedbenefit private pension, contracted-out rates of employee NICs were 2.5 percentage points lower and employer NICs 4.5 percentage points lower than contracted-in rates in 1978-79, falling to 1.4 percentage points and 3.4 percentage points respectively by 2015-16. The contracted-out rebate for those contributing to a defined-contribution pension varied by age.

Prior to 1997 our data do not record whether people were contracted in or out, and therefore we have to make an assumption on which NICs rates to use. We assume that everyone was contracted out. This is partly because, over the period as a whole - and especially in the years that provide most of our identifying variation - the majority of employees were contracted out. ${ }^{7}$ Moreover, even for those employees who were contracted in, the contracted-out rate is arguably a better measure of the 'tax wedge' associated with NICs: the additional NICs associated with contracting in generates additional future pension entitlements on a roughly actuarially fair basis, so resembles retirement saving more than a tax insofar as people value these future entitlements. ${ }^{8}$ We are therefore stripping out this 'savings' element of National Insurance and focusing on the pure tax wedge. But in any case, the main reforms we use for the purposes of identification applied to both the contracted-in and contracted-out schedules of NICs.

Note that the lower contracted-out rates applied only to earnings above the LEL, even when those above it were taxed on their earnings below the threshold as well. Thus, for example, when we use contracted-out rates the NICs schedule at the start of 1985

\footnotetext{
${ }^{5}$ For details of contributory benefits, see Hood and Oakley (2014a). The decline of the 'contributory principle' is discussed by Adam and Loutzenhiser (2007) and Hood and Oakley (2014b), among others.

${ }^{6}$ For those contributing to a defined-benefit private pension, contracted-out rates of employee NICs were 2.5 percentage points lower and employer NICs 4.5 percentage points lower than contracted-in rates in 1978-79, falling to 1.4 percentage points and 3.4 percentage points respectively by $2012-13$. The contracted-out rebate for those contributing to a defined-contribution pension varied by age.

${ }^{7}$ The contracted-out rates we use are those applying to employees contracted out into a defined-benefit pension scheme, which was much more common than contracting out into a defined-contribution scheme. Source: Department for Work and Pensions Statistics, http://tabulationtool.dwp.gov.uk/NIRS/live/tabtool.html.

${ }^{8}$ Bear in mind that those contracting in were choosing to pay these extra NICs when others were choosing not to, suggesting that they did value the entitlements they got in return. Disney, Emmerson and Wakefield (2008) provide evidence that people responded remarkably rationally when contracted-out rebates did depart from actuarial fairness.
} 
described above still involves a jump in the average rate from zero to the headline (contracted-in) rates of $9 \%$ (employees) and $10.45 \%$ (employers) as described in the text, but the marginal rate increased from zero to the contracted-out rates of $6.85 \%$ (employees) and 6.35\% (employers) rather than the same headline rates given above. This is reflected in Figure 1 and Table 1.

As well as contracting in, there were some other (weak) links between NICs rates and benefit entitlements, particularly in the early part of the period we analyse. But crucial for our purposes is that none of the changes in contribution rates over this period was associated with a corresponding change in entitlements. When an individual in our data sees their NICs rate rise, it simply changes their current budget constraint, just like a tax; they do not acquire additional implicit savings or insurance which they might value. The only reason we might expect people to respond to changes in NICs differently from another tax on earnings is if they (wrongly) perceive it differently. 
Table 1. Rates and thresholds of National Insurance contributions, 1978-79 to 2015-16

\begin{tabular}{|c|c|c|c|c|c|c|c|c|}
\hline \multirow[t]{2}{*}{ Yeara } & \multirow{2}{*}{$\begin{array}{l}\text { Threshold } \\
\text { (£ p.w.) }\end{array}$} & \multirow{2}{*}{$\begin{array}{l}\text { Upper earnings } \\
\text { limit } \\
\text { (£ p.w.) }\end{array}$} & \multicolumn{3}{|c|}{ Employee contributions } & \multicolumn{3}{|c|}{ Employer contributions } \\
\hline & & & $\begin{array}{c}\text { Rate at threshold } \\
(\%)\end{array}$ & $\begin{array}{c}\text { Main rate(s) } \\
\quad(\%)\end{array}$ & $\begin{array}{l}\text { Rate above } \\
\text { UEL (\%) }\end{array}$ & $\begin{array}{c}\text { Rate at threshold } \\
(\%)\end{array}$ & $\begin{array}{c}\text { Main rate(s) } \\
(\%)\end{array}$ & $\begin{array}{l}\text { Rate above } \\
\text { UEL (\%) }\end{array}$ \\
\hline $1978-79$ & $£ 17.50$ & $£ 120.00$ & 6.5 & 4 & 0 & 10 & 7.5 & 0 \\
\hline $1979-80$ & $£ 19.50$ & $£ 135.00$ & 6.5 & 4 & 0 & 10 & 9.0 & 0 \\
\hline 1980-81 & $£ 23.00$ & $£ 165.00$ & 6.75 & 4.25 & 0 & 10.2 & 9.2 & 0 \\
\hline 1981-82 & $£ 27.00$ & $£ 200.00$ & 7.75 & 5.25 & 0 & 10.2 & 9.2 & 0 \\
\hline $1982-83$ & $£ 29.50$ & $£ 220.00$ & 8.75 & 6.25 & 0 & 10.2 & 9.2 & 0 \\
\hline 1983-84 & $£ 32.50$ & $£ 235.00$ & 9 & 6.85 & 0 & 10.45 & 7.85 & 0 \\
\hline 1984-85 & $£ 34.00$ & $£ 250.00$ & 9 & 6.85 & 0 & 10.45 & 7.35 & 0 \\
\hline $1985-86$ & $£ 35.50$ & $£ 265.00$ & 9 & 6.85 & 0 & 10.45 & 6.35 & 0 \\
\hline 1986-87 & $£ 38.00$ & $£ 285.00$ & 5 & $2.85-6.85$ & 0 & 5 & $0.9-6.35$ & 10.45 \\
\hline 1987-88 & $£ 39.00$ & $£ 295.00$ & 5 & $2.85-6.85$ & 0 & 5 & $0.9-6.35$ & 10.45 \\
\hline 1988-89 & $£ 41.00$ & $£ 305.00$ & 5 & $3-7$ & 0 & 5 & $1.2-6.65$ & 10.45 \\
\hline $1989-90$ & $£ 43.00$ & $£ 325.00$ & 5 & $3-7$ & 0 & 5 & $1.2-6.65$ & 10.45 \\
\hline 1990-91 & $£ 46.00$ & $£ 350.00$ & 2 & 7 & 0 & 5 & $1.2-6.65$ & 10.45 \\
\hline $1991-92$ & $£ 52.00$ & $£ 390.00$ & 2 & 7 & 0 & 4.6 & $0.8-6.6$ & 10.4 \\
\hline $1992-93$ & $£ 54.00$ & $£ 405.00$ & 2 & 7 & 0 & 4.6 & $0.8-6.6$ & 10.4 \\
\hline 1993-94 & $£ 56.00$ & $£ 420.00$ & 2 & 7.2 & 0 & 4.6 & $1.6-7.4$ & 10.4 \\
\hline 1994-95 & $£ 57.00$ & $£ 430.00$ & 2 & 8.2 & 0 & 3.6 & $0.6-7.2$ & 10.2 \\
\hline $1995-96$ & $£ 58.00$ & $£ 440.00$ & 2 & 8.2 & 0 & 3 & $0-7.2$ & 10.2 \\
\hline $1996-97$ & $£ 61.00$ & $£ 455.00$ & 2 & 8.2 & 0 & 3 & $0-7.2$ & 10.2 \\
\hline 1997-98 & $£ 62.00$ & $£ 465.00$ & 2 & 8.2 & 0 & 3 & $0-7$ & 10 \\
\hline 1998-99 & $£ 64.00$ & $£ 485.00$ & 2 & 8.4 & 0 & 3 & $0-7$ & 10 \\
\hline 1999-00 & $£ 66.00^{a}$ & $£ 500.00$ & 0 & 8.4 & 0 & 0 & 9.2 & 12.2 \\
\hline 2000-01 & $€ 76.00^{\mathrm{b}}$ & $£ 535.00$ & 0 & 8.4 & 0 & 0 & 9.2 & 12.2 \\
\hline
\end{tabular}




\begin{tabular}{|c|c|c|c|c|c|c|c|c|}
\hline 2001-02 & $£ 87.00$ & $£ 575.00$ & 0 & 8.4 & 0 & 0 & 8.9 & 11.9 \\
\hline $2002-03$ & $£ 89.00$ & $£ 585.00$ & 0 & 8.4 & 0 & 0 & 8.3 & 11.8 \\
\hline 2003-04 & $£ 89.00$ & $£ 595.00$ & 0 & 9.4 & 1 & 0 & 9.3 & 12.8 \\
\hline 2004-05 & $£ 91.00$ & $£ 610.00$ & 0 & 9.4 & 1 & 0 & 9.3 & 12.8 \\
\hline $2005-06$ & $£ 94.00$ & $£ 630.00$ & 0 & 9.4 & 1 & 0 & 9.3 & 12.8 \\
\hline 2006-07 & $£ 97.00$ & $£ 645.00$ & 0 & 9.4 & 1 & 0 & 9.3 & 12.8 \\
\hline 2007-08 & $£ 100.00$ & $£ 670.00$ & 0 & 9.4 & 1 & 0 & 9.1 & 12.8 \\
\hline 2008-09 & $£ 105.00$ & $£ 770.00$ & 0 & 9.4 & 1 & 0 & 9.1 & 12.8 \\
\hline $2009-10$ & $£ 110.00$ & $£ 844.00$ & 0 & 9.4 & 1 & 0 & 9.1 & 12.8 \\
\hline $2010-11$ & $£ 110.00$ & $£ 844.00$ & 0 & 9.4 & 1 & 0 & 9.1 & 12.8 \\
\hline 2011-12 & $£ 139.00^{c}$ & $£ 817.00$ & 0 & 10.4 & 2 & 0 & 10.1 & 13.8 \\
\hline $2012-13$ & $£ 146.00^{\mathrm{d}}$ & $£ 817.00$ & 0 & 10.6 & 2 & 0 & 10.4 & 13.8 \\
\hline $2013-14$ & $£ 149.00^{\mathrm{e}}$ & $£ 797.00$ & 0 & 10.6 & 2 & 0 & 10.4 & 13.8 \\
\hline 2014-15 & $£ 153.00$ & $£ 805.00$ & 0 & 10.6 & 2 & 0 & 10.4 & 13.8 \\
\hline $2015-16$ & $£ 155.00^{\mathrm{f}}$ & $£ 815.00$ & 0 & 10.6 & 2 & 0 & 10.4 & 13.8 \\
\hline
\end{tabular}

Notes: Assumes employee contracted out of the State Earnings-Related Pension Scheme (SERPS) or State Second Pension (S2P) into a defined-benefit private pension scheme. In years where the Lower Earnings Limit differed from the Threshold shown here (i.e. since 1999-2000), or where the Upper Accrual Point differed from the Upper Earnings Limit shown here (i.e. since 2009-10), slightly different rates applied in those small bands of earnings. When the NICs schedule changed during a fiscal year, parameters shown are those applying at the start (April) of the year, which is when our data are observed. For more detail of all of these see the source given below.
(a) $\mathrm{f} 83$ for employer contributions.
(b) $£ 84$ for employer contributions.
(c) $£ 136$ for employer contributions.
(d) $\mathrm{f} 144$ for employer contributions.
(e) $£ 148$ for employer contributions.
(f) $£ 156$ for employer contributions.

Source: IFS Fiscal Facts, http://www.ifs.org.uk/tools and resources/fiscal facts/. 


\section{Literature Review}

Interest in the extent to which labour supply and demand respond to taxation, and the economic incidence of labour taxes, is longstanding in applied economics (Blundell and Macurdy (1999), Fullerton and Metcalf (2002), Hamermesh (1996)). The scale of these supply and demand responses are a key driver of the efficiency costs of labour taxation (and the revenue generated by a given tax or tax reform). Of course, the issues of behavioural response and incidence are intimately linked: it is the relative responsiveness of labour supply and demand that determines labour tax incidence in a classical labour market.

Following the seminal work by Feldstein $(1995,1999)$, the NTR literature shifted the focus of the analysis of the behavioural effects of taxation from the estimation of hoursof-work elasticities to taxable income elasticities. Changes in total taxable income may reflect not only changes in hours of work, but also changes in hourly wages, changes in non-labour income, and changes in tax avoidance (such as shifting income into untaxed forms) and tax evasion (such as not reporting income). Under certain conditions, Feldstein (1995) demonstrated that this overall response of total taxable income to the net-of-marginal tax rate is a summary statistic of the deadweight losses due to taxation.

A large literature has subsequently developed estimating elasticities of taxable income, mostly in the US, but more recently in Western Europe as well: see Saez et al (2012) for a review. A number of papers examine the responsiveness of specifically labour income to taxation, finding a lesser degree of responsiveness than for overall taxable income. Blomquist and Selin (2010) find a taxable earnings elasticity of 0.2 for Swedish men; Saez (2003) finds a statistically insignificant taxable earnings elasticity of 0.1 for the US; and Kleven and Schultz (2014) find an elasticity of 0.05-0.12 in Denmark. ${ }^{9}$

Relatively few studies have attempted to estimate the elasticity of taxable earnings with respect to the SSC rate in a similar manner (analysis of SSCs has instead tended to focus on tax incidence, as discussed below). Two recent papers, Tazhitdinova (2016) and Adam et al. (2016), both find little bunching of employees' earnings at NICs thresholds in the UK (though evidence of greater responsiveness among those in business); Tazhitdinova (2016) interprets this as implying elasticities of 0.05-0.09, while Adam et al. (2016) emphasise evidence of large and heterogeneous frictions which significantly attenuate such estimates of elasticities. Methodologically closer to the present analysis, Lehmann et al (2013) uses reforms to France's income tax credits and employer SSCs to separately estimate the elasticity of labour cost (gross earnings plus employer SSCs) to the net-of-marginal and net-of-average income tax and SSC rates. They find a statistically significant elasticity with respect to the net-of-marginal income tax rate of

\footnotetext{
${ }^{9}$ Kleven and Schultz (2014) indeed find that taxable income elasticities are greater for capital income than labour income, and for deductions than positive income.
} 
0.2 , but virtually no effect of the net-of-marginal employer SSC rate on labour cost. They find an elasticity with respect to the net-of-average income tax rate of -0.44 (although this is statistically insignificant), and an elasticity with respect to the net-of-average

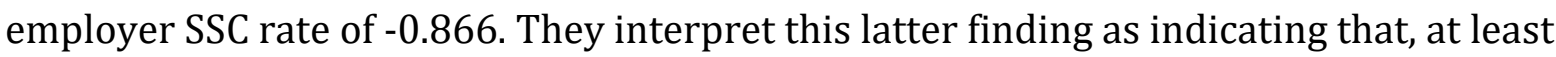
in the short term, the statutory incidence of employers' SSCs matters: employers bear the cost of these in the form of higher costs, rather than workers in the form of lower wages. ${ }^{10}$

An implicit maintained assumption in most of the rest of the NTR literature is that the incidence of taxes is on the individual in question, rather than, for instance, their employer. This is what allows estimated coefficients on net-of-marginal and net-ofaverage tax rates to be interpreted as individual responses to taxation. Saez et al (2012) point out that, following Diamond and Mirrlees (1971), shifting of the burden of taxation does not affect its overall efficiency cost, nor optimal tax rates. Nevertheless, if the assumption of full incidence on the employee is relaxed, estimated responses to netof-marginal tax rates would reflect responses by both sides of the market (not just the individual taxpayer in question), and estimated responses to net-of-average tax rates would at least in part reflect the incidence of a tax, and not only income effects.

The literature on the incidence of labour taxation, on the other hand, largely ignores the issue of non-hours-of-work labour supply responses that are at the heart of the NTR literature. Seminal papers by Gruber (1997) and Anderson and Meyer (1997, 2000), for instance, examine the impact on earnings and employment of changes in SSCs that affect different firms differently in Chile and the United States, respectively. Gruber (1997) finds that establishment-level earnings increased roughly one-for-one with reductions in establishment-level employers' SSCs, while establishment-level employment was unaffected. Anderson and Meyer $(1997,2000)$ find broadly similar results for earnings for industry-level changes in employers' SSCs (although the link between earnings and establishment-level changes in employers' SSCs is much weaker). In both instances the authors interpret these earnings effects as evidence that the incidence of employer SSCs in question is largely, or fully, on workers. But it could be the case that part of the change in observed earnings when SSCs change instead reflects increases in (say) effort or income shifting induced by the tax change. In other words, there is the risk that such behavioural responses confound estimates of tax incidence. ${ }^{11}$

Notwithstanding these issues, Melguizo and González-Páramo (2013) undertake a review and meta-analysis of the incidence literature ${ }^{12}$ and find that, on average, studies find around one-third of the burden of labour taxes is borne by employers - or more

\footnotetext{
${ }^{10}$ As discussed below, assuming away income effects, an 'elasticity' of labour cost with respect to the net-ofaverage social security tax rate of -1 would indicate full incidence on the employer. The estimate of -0.866 is not statistically different from this.

${ }^{11}$ The same applies to papers such as Kubik (2004), Leigh (2010) and Rothstein (2010), which examine the incidence of income tax and earned income tax credit rather than social security contributions.

${ }^{12}$ Which also includes studies making use of cross-country time-series analysis, relating changes in average earnings or labour-income shares to changes in labour taxes.
} 
correctly their shareholders, suppliers or customers - and two-thirds by employees, but that there is a very wide range of estimates. ${ }^{13}$ Some studies, such as Gruber (1997), find almost full incidence of employers' SSCs on workers, while others find the incidence remains on employers. Most studies examine short-term incidence (Lehmann et al (2013), Bunel and L'Horty (2012)), but a few suggest longer-run incidence on employers (Saez et al (2012b)).

In a frictionless classical labour market model, the formal incidence of a tax should not matter for its economic incidence. Wages should adjust, based on the relative elasticities of labour supply and demand, irrespective on which side of the market a tax is formally levied. Relatively few studies directly examine this Invariance of Incidence Proposition (IIP), however. This probably reflects the fact that many countries' reforms to SSCs affect employee and employer contributions simultaneously and highly co-linearly, making identification of separate effects difficult. Among those studies that do, which are mainly based on cross-country regressions (such as OECD (1990) and Arpaia and Carone (2004)), there is evidence that the IIP is violated in the short-term, perhaps reflecting short-term stickiness of nominal wages. Whether the IIP holds in the longerrun is less clear, in part because of weak statistical power in the long-run analyses contained the papers that examine this issue (CPB et al (2015)).

By utilising a long time period in which there were separate reforms to employee and employer SSCs, we can examine the IIP. As discussed further below, we also examine slightly longer-run effects of changes in SSCs and income taxes on earnings and hours of work by including lagged changes in the relevant tax rates.

Bingley and Lanot (2002) is a rare example of a paper which unites the NTR and tax incidence literatures, utilising sub-national variation in tax rates across employees and employers to identify incidence and behavioural responses separately. This source of variation does not exist in the UK. We instead use two approaches and sets of assumptions to analyse incidence and behavioural responses to taxation. The first, following the approach generally taken in the incidence literature, involves examining changes in hourly labour cost (defined as wages plus employers' SSCs) and hours of work, and requires assumptions about non-hours responses to changes in tax rates in order to separately identify behavioural effects and incidence. The second involves examining overall changes in a workers' cost to their employer (e.g. per week or per month). Assumptions on income effects are then required to separately identify behavioural effects and incidence (or, conversely, assumptions on incidence are required to identify income effects).

\section{Approaches to identifying incidence and behaviour}

Our methodology builds on the work of Lehmann et al. (2013). Indeed, we start with the same simple behavioural function determining labour cost, $Z$ :

${ }^{13}$ A more narrative review is available in CPB et al (2015). 


$$
Z=Z\left(\tau^{R}, \tau^{E}, R^{R}, R^{E}\right)
$$

Where $\tau^{R}$ and $\tau^{E}$ are the net-of-marginal employer and employee NICs rates respectively, and $R^{R}$ and $R^{E}$ are the virtual net-of-all-NICs and net-of-employer-NICs incomes. Lehmann et al. (2013) show that differentiating with respect to the various features of the tax system and rearranging, one can obtain the following expression:

$$
\frac{\Delta Z}{Z}=\beta_{Z, \tau}^{R} \frac{\Delta \tau^{R}}{\tau^{R}}+\beta_{Z, \tau}^{E} \frac{\Delta \tau^{E}}{\tau^{R E}}+\beta_{Z, \rho}^{R} \frac{\Delta \rho^{R} \mid}{\rho^{R}}+\beta_{Z, \rho}^{E} \frac{\Delta \rho^{E} \mid}{\rho^{E}}
$$

where $\rho^{R}$ is the net-of-average employer NICs rate (i.e. gross earnings divided by labour cost), and $\rho^{E}$ is the net-of-average employee NICs rate (i.e. net earnings divided by gross earnings). $\Delta \rho^{R} \mid$ and $\Delta \rho^{E} \mid$ are the changes in these net-of-average NICs rates calculated holding earnings fixed at their initial (pre-reform) level, which differ from the actual changes $\left(\Delta \rho^{R}\right.$ and $\left.\Delta \rho^{E}\right)$ if the NICs schedule is not proportional and employees or employers respond to changes in NICs by changing their labour supply or labour demand. Lehmann et al. (2013) show that using the actual change in average tax rates or virtual income (as is usually done in the NTR literature following Gruber and Saez (2002)) may lead to inconsistent estimates, even if instrumented for.

The coefficients $\beta_{Z, \tau}^{R}$ and $\beta_{Z, \tau}^{E}$ denote elasticities of labour cost with respect to compensated changes in net-of-marginal employer and employee NICs, respectively. The standard interpretation of these coefficients in the NTR literature is as compensated labour supply or other individual responses (i.e. pure substitution effects). If one allows for less than perfectly elastic labour demand - and therefore the prospect of at least partial incidence of NICs on employers - the coefficients will pick up a combination of compensated labour supply and labour demand effects.

Similarly, the coefficient on net-of-average NICs rates $\left(\beta_{Z, \rho}^{R}\right.$ and $\left.\beta_{Z, \rho}^{E}\right)$ would generally be assumed to capture income effects. However, these coefficients will also capture the incidence of NICs changes: shifting of the burden of NICs means labour costs rising/falling as the total amount of NICs charged - reflected in the average net-of-NICs rate - changes. ${ }^{14}$

So (how) can we separate out incidence and income effects? It is impossible to do so purely by looking at labour cost responses to tax rate changes without making additional assumptions. For example, if labour cost increases in response to an increase in the average rate of employee NICs, that could reflect employees' working harder to make up the loss of income (a standard income effect) or some shifting of the burden of the tax increase onto employers (without necessarily any change in the amount of work being done). As already discussed, most of the existing NTR and incidence literatures implicitly assume away one or other of these possibilities.

\footnotetext{
${ }^{14}$ In other contexts the average tax rate should also capture extensive margin (i.e. employment) responses, but since we condition our sample on being observed in employment we do not estimate standard extensive margin responses in this paper.
} 
We take two approaches.

\section{Assumptions on incidence or income effects}

Our first approach is simply to analyse what alternative assumptions would imply for the interpretation of our results. Specifically, we could (a) assume that labour demand is perfectly elastic and the incidence of NICs is therefore fully and immediately on employees, so responses to average tax rates reflect income effects. Alternatively, we could (b) assume that income effects are negligible so that earnings responses to average NICs rates reflect the incidence of the change. ${ }^{15}$ (Of course, the reality may be somewhere between these two extreme assumptions, meaning $\beta_{Z, \rho}^{R}$ and $\beta_{Z, \rho}^{E}$ pick up some combination of income effects and incidence.) Under assumption (b), in principle, the estimate of NICs incidence - which in a classical labour market would reflect the relative elasticities of labour supply and demand - could be used to back out the labour supply and demand elasticities from the overall compensated elasticities with respect to marginal rates, $\beta_{Z, \tau}^{R}$ and $\beta_{Z, \tau}^{E}$. Table 2 shows the values the various coefficients would be expected to take under these different assumptions.

Row (1) shows what we would expect if labour demand is fully elastic and the incidence of both employee and employer NICs is on the employee. $\beta_{Z, \tau}^{R}$ and $\beta_{Z, \tau}^{E}$ pick up compensated labour supply responses and should therefore be greater than or equal to 0 , and in most standard models of the labour market should be equal to each other. The coefficients on net-of-average tax rates would pick up income effects and should also be equal to each other, but in this case should be less than or equal to 0 . If coefficients for employee or employer differ from each other, non-standard features such as differing salience of the two taxes may play a role (Chetty et al. (2009), Lehmann et al. (2013)).

The following rows rule out income effects. Row (2) shows what would happen if labour demand were less than fully elastic and the incidence of NICs were shared between employees and employers. $\beta_{Z, \tau}^{R}$ and $\beta_{Z, \tau}^{E}$ would pick up a combination of compensated labour supply and labour demand responses and should therefore be greater than or equal to 0 . The coefficients on net-of-average tax rates would pick up the shifting of employee NICs partly on to employers and vice versa, and would therefore lie between -1 , where labour costs change 1 -for- 1 with NICs (i.e. full incidence on employers) and 0 , where labour costs are unaffected by NICs (i.e. full incidence on employees). This is similar to what would be observed if incidence was fully on employees but there were income effects. It is therefore difficult to distinguish between income effects and the sharing of the burden of SSCs between employers and employees. In practice coefficients on net-of-average tax rates are likely to pick up both income effects and incidence.

\footnotetext{
${ }^{15}$ It would be possible to take this further to consider alternative, more complicated assumptions, most obviously assuming some particular non-zero size of income effects or some particular degree of shifting.
} 
Table 2. Expected coefficient values in a labour cost $(Z)$ regression under various assumptions about incidence and income effects

\begin{tabular}{llcccc}
\hline & & \multicolumn{2}{c}{ Net-of-marginal } & \multicolumn{2}{c}{ Net-of-average } \\
& & \multicolumn{2}{c}{ rate coefs. } & \multicolumn{2}{c}{ rate coefs. } \\
& & $\beta_{Z, \tau}^{R}$ & $\beta_{Z, \tau}^{E}$. & $\beta_{Z, \rho}^{R}$ & $\beta_{Z, \rho}^{E}$ \\
\hline (1) $\quad$ Full incidence on employee & & $\geq 0$ & $\geq 0$ & $\leq 0$ & $\leq 0$ \\
Assuming no income effects: & & & & \\
(2) $\quad$ Sharing of incidence & & & & \\
(3) $\quad$ Full incidence on employer & & $\geq 0$ & $\geq 0$ & $-1<\beta<0$ & $-1<\beta<0$ \\
(4) $\quad$ Statutory incidence & d & $\geq 0$ & $\geq 0$ & -1 & -1 \\
\hline
\end{tabular}

Notes: (a) In standard models, furthermore, $\beta_{Z, \tau}^{R}=\beta_{Z, \tau}^{E}$ and $\beta_{Z, \rho}^{R}=\beta_{Z, \rho}^{E}$.

(b) In standard models, furthermore, $\beta_{Z, \tau}^{R}=\beta_{Z, \tau}^{E}$ and $\beta_{Z, \rho}^{R}=\beta_{Z, \rho}^{E}$.

(c) Unless labour supply is fully elastic, full incidence on employers requires $\beta_{Z, \tau}^{R}=\beta_{Z, \tau}^{E}=0$.

(d) Statutory incidence requires models with at least temporary gross wage stickiness.

Row (3) shows the values the coefficients would take if taxes were fully incident on employers. Labour cost would move one-for-one with changes in net-of-average NICs rates $\left(\beta_{Z, \rho}^{R}=\beta_{Z, \rho}^{E}=-1\right)$.

Row (4) shows what we would expect if economic incidence followed statutory incidence. Changes in average rates of employee NICs would be borne by employees, leaving labour cost unaffected $\left(\beta_{Z, \rho}^{E}=0\right)$, while changes in average rates of employee NICs would be borne by employers and affect labour cost one-for-one $\left(\beta_{Z, \rho}^{R}=-1\right)$. $\beta_{Z, \tau}^{E}$ would pick up compensated labour supply responses to employee NICs and would be greater than or equal to 0 .

Lehmann et al. (2013) state that $\beta_{Z, \tau}^{R}$ would equal 0 in such circumstances. This may reflect the fact that in standard labour market models, employers would only bear the burden of NICs if their labour demand was perfectly inelastic. However, for economic incidence to follow statutory incidence in this manner requires a degree of gross earnings stickiness. If employers and employees (or their representatives) contract on the basis of gross wages/earnings, as is generally the case, it may take some time for wages/earnings to adjust following changes in employee and/or employer NICs rates. Thus it may not be surprising to find economic incidence following formal incidence in the short term. Indeed, if employers and employees also bargain over these gross earnings levels, in some models of the labour market, formal incidence may matter for economic incidence on a more long-term basis (perhaps explaining the findings of Saez et al (2012b)). But in such models, it need not be the case that labour demand is completely inelastic for employer NICs to be incident on employers. Thus we might expect $\beta_{Z, \tau}^{R} \geq 0$ rather than $\beta_{Z, \tau}^{R}=0$.

It is also possible for the coefficients on net-of-average NICs rates, $\beta_{Z, \rho}^{E}$ and/or $\beta_{Z, \rho}^{R}$, to be $<-1$. This could occur, for instance, if there were more than $100 \%$ incidence of NICs 
changes on employers (possible in some imperfectly competitive models of the labour markets), or if full or close to full incidence of a tax on employers were combined with income effects.

\section{Using data on hours of work}

The second approach we take exploits the availability of hours of work in our data. In particular, we estimate the empirical counterparts to the following hours-of-work and hourly-labour-cost equations:

$$
\begin{aligned}
& \frac{\Delta H}{H}=\beta_{H, \tau}^{R} \frac{\Delta \tau^{R}}{\tau^{R}}+\beta_{H, \tau}^{E} \frac{\Delta \tau^{E}}{\tau^{E}}+\beta_{H, \rho}^{R} \frac{\Delta \rho^{R} \mid}{\rho^{R}}+\beta_{H, \tau}^{E} \frac{\Delta \rho^{E} \mid}{\rho^{E}} \\
& \frac{\Delta(Z / H)}{(Z / H)}=\beta_{Z / H, \tau}^{R} \frac{\Delta \tau^{R}}{\tau^{R}}+\beta_{Z / H, \tau}^{E} \frac{\Delta \tau^{E}}{\tau^{E}}+\beta_{Z / H, \rho}^{R} \frac{\Delta \rho^{R} \mid}{\rho^{R}}+\beta_{Z / H, \tau}^{E} \frac{\Delta \rho^{E} \mid}{\rho^{E}}
\end{aligned}
$$

where $H$ is hours of work and $Z / H$ is hourly labour cost.

If we assume that behavioural responses to NICs operate entirely through hours of work, then those labour supply and labour demand responses should be identified in equation (4.3), while the coefficients on net-of-average tax rates in equation (4.4) $\left(\beta_{Z / H, \rho}^{R}, \beta_{Z / H, \rho}^{E}\right)$ would capture the incidence of NICs changes.

In an hours-of-work regression corresponding to equation (4.3), the coefficients would have the same expected signs etc. shown in Table 2, except that in the absence of income effects (rows 2-4) the expected coefficients on net-of-average tax rates $\left(\beta_{H, \rho}^{R}, \beta_{H, \rho}^{E}\right)$ would be expected to be zero since changes in hours (unlike labour cost) should not be picking up incidence.

If all behavioural responses operate through hours of work, responses of hourly labour costs to NICs rates in equation (4.4) should only reflect shifting of the incidence of the tax and the incidence can be inferred from coefficients on net-of-average NICs rates $\left(\beta_{Z / H, \rho}^{R}, \beta_{Z / H, \rho}^{E}\right)$, with interpretations as in Table 2 . Without this assumption, the coefficients in an hourly labour cost regression could pick up both incidence and behavioural effects as in an overall labour cost regression.

Assuming that behavioural responses to NICs operate entirely through hours of work means ruling out the kinds of non-working-hours behavioural responses to taxation which, in part, motivated the NTR literature: notably effort per hour, but also other behavioural responses that operate through the observed hourly wage, such as shifting to/from unobserved forms of remuneration that are not subject to the tax change. We cannot test this assumption per se, but note that if substitution effects operate entirely through hours of work then we would expect marginal tax rates to have no effect on hourly labour costs (since incidence should be a function of the average rate, not the marginal rate), so we can test this by looking whether marginal rates are significant in our hourly labour costs regression (i.e. test whether we can reject the hypotheses that 
$\beta_{Z / H, \tau}^{R}$ and $\left.\beta_{Z / H, \tau}^{E}=0\right)$. In principle it is possible that income effects operate through the hourly wage but substitution effects do not, or vice versa, but this evidence should at least be suggestive.

\section{Econometric methodology}

As discussed above, the objective of our analysis is to identify the responsiveness of labour cost, hours of work, and labour cost per hour to employer and employee SSCs. Furthermore by placing certain restrictions on assumed behaviour - such as the absence of income effects, or of non-hours labour supply responses -, it is possible to interpret findings as indicating the extent of incidence-shifting and underlying behavioural (labour supply and demand) responses.

We take our lead from Lehmann et al (2013), and estimate the following empirical counterparts to equations $4.2,4.3$ and 4.4 :

$$
\begin{gathered}
\Delta \ln Z_{i, t}=\alpha_{Z}+\beta_{Z, \tau}^{R} \Delta \ln \tau_{i, t}^{R}+\beta_{Z, \tau}^{E} \Delta \ln \tau_{i, t}^{E}+\beta_{Z, \rho}^{R} \Delta \ln \rho_{i, t}^{R}\left|+\beta_{Z, \rho}^{E} \Delta \ln \rho_{i, t}^{E}\right|++\gamma_{Z} \boldsymbol{X}_{i, t}+\varepsilon_{i, t, Z} \\
\Delta \ln H_{i, t}=\alpha_{H}+\beta_{H, \tau}^{R} \Delta \ln \tau_{i, t}^{R}+\beta_{H, \tau}^{E} \Delta \ln \tau_{i, t}^{E}+\beta_{H, \rho}^{R} \Delta \ln \rho_{i, t}^{R}\left|+\beta_{H, \rho}^{E} \Delta \ln \rho_{i, t}^{E}\right|+\gamma_{H} \boldsymbol{X}_{i, t}+\varepsilon_{i, t, H}
\end{gathered}
$$

$$
\begin{gathered}
\Delta \ln (Z / H)_{i, t}=\alpha_{Z / H}+\beta_{Z / H, \tau}^{R} \Delta \ln \tau_{i, t}^{R}+\beta_{Z / H, \tau}^{E} \Delta \ln \tau_{i, t}^{E}+\beta_{Z / H, \rho}^{R} \Delta \ln \rho_{i, t}^{R}\left|+\beta_{Z / H, \rho}^{E} \Delta \ln \rho_{i, t}^{E}\right|+ \\
\gamma_{Z / \boldsymbol{H}} \boldsymbol{X}_{\boldsymbol{i}, \boldsymbol{t}}+\varepsilon_{i, t, Z / H}
\end{gathered}
$$

Where changes in labour cost, etc., are calculated for periods of 1 year in length. $\boldsymbol{X}_{\boldsymbol{i}, \boldsymbol{t}}$ is a vector of controls, including time period dummies (to pick up, for instance, the effect of inflation, in 5.1 and 5.3), and controls for differential trends in different parts of the labour costs or hours distributions. $\varepsilon_{i, t}$ is an error term that captures unobserved and time-varying heterogeneity.

It is well known from the labour supply and NTR literatures that various issues arise with estimation of such equations. The first is a potential simultaneity bias. Because of the nonlinearity of the employee and employer NICs schedules, the marginal net-of-tax rates $\tau_{i, t}^{E}$ and $\tau_{i, t}^{R}$ are functions labour cost, hours or hourly labour cost. Thus, to identify the effect of NICs on labour cost, hours, etc, instruments are required.

The long-standing standard approach to this problem, proposed by Auten and Caroll (1999), uses changes in the log net-of-tax rates holding earnings unchanged at their $\mathrm{t}-1$ level (adjusted only for inflation, or average earnings growth, say) as such an instrument. This approach controls for the further problems of differential secular trends in income and mean reverting income processes by including functions of t-1 and t-2 earnings in the regression. However, Weber (2014) shows that instruments based on $\mathrm{t}-1$ earnings cannot be exogenous if there is mean reversion. 
Instead, Weber proposes to instrument for changes in the net of tax rate using changes in these tax rates calculated holding income/earnings fixed at its level in period t-1-k, (rather than period t-1). The lag k should be chosen so that it is far enough before the period in question so that income/earnings in period t-1-k are unaffected by any transitory shocks affecting income/earnings in period $\mathrm{t}-1$, but not so far that the instrument is a poor predictor of the actual change in tax rate observed. Further, Weber argues that one can test for whether a particular instrument is exogenous, conditional upon the assumption that other excluded instruments (for example, based on longerlags) are exogenous using a Difference-in-Sargan test. Using US income tax data from the 1980s she finds that she cannot reject that instruments based on income in period t2 (i.e. $k=1$ ) are exogenous (p-value: 0.229 ), but her preferred specification is based on instruments based on income in period t-3 (p-value: 0.858 ).

Lehmann et al (2013) use changes in net-of-tax rates calculated at earnings held fixed at their levels in period t-2 (i.e. $\mathrm{k}=1$ ) as their type-II instruments. In this paper, we use such instruments in our main specification, following testing of them using Differencein-Sargan tests. As with Weber, we reject the exogeneity of instruments based on earnings in period $t-1$, even when controls are included (p-values of $0.00-0.01$, depending on precise specification). We cannot reject the exogeneity of our preferred type-II instruments based on earnings in period t-2 (p-values of $0.15-0.7$ ). We also report, in Appendix X, results estimated using instruments based on earnings in period $\mathrm{t}-3$ to examine the robustness of our main specification.

While our use of Weber-type instruments should, hopefully, deal with the problem of mean reversion, it will not deal with the problem of longer-term differential earnings trends. For instance, during the 1980s, earnings inequality was increasing significantly in the UK (Blundell and Etheridge (2010)). At the same time, changes in NICs (most notably in 1985) reduced average NICs rates at the bottom of the earnings distribution, and increased them at the top. The risk is that one would inappropriately attribute those changes in labour cost, for instance, that relate to these non-tax factors to the tax reform instead, biasing estimated coefficients. To control for differential trends in earnings and hours at different parts of the distribution, we include controls based on $\ln Z_{i, t-2}$.

\section{Behaviour and incidence in the longer-run}

Examining changes in labour cost, hours and labour cost per hour between period t-1 and $t$, and relating this to changes in tax rates between period $t-1$ and $t$ allows one to pick up only very short-run behavioural effects and incidence shifting given many tax reforms take place at the start of April, the point at which our data is collected (see below). Frictions in behaviour and earnings are likely to mean that it takes some time for individuals and employers to respond to tax policy changes.

The traditional response to this problem is to use panel lengths of longer than one year. For instance, rather than calculating $\Delta \ln Z_{i, t}=\ln Z_{i, t}-\ln Z_{i, t-1}$, instead calculating 
$\Delta \ln Z_{i, t}=\ln Z_{i, t}-\ln Z_{i, t-2}$ or $\Delta \ln Z_{i, t}=\ln Z_{i, t}-\ln Z_{i, t-3}$. This is the approach taken in Gruber and Saez (2002), who stack these 3-year changes (so that their estimates are based on changes in incomes and tax rates between 1979 and 1982, 1980 and 1983, 1981 and 1984, etc). However such an approach does not actually estimate responses after 3 years.

To see this, consider a policy change occurring in period T. Estimates based on the changes between period T- 1 and $\mathrm{T}+2$ will pick up the effects of the policy change after 2 periods; estimates based on the change between period $\mathrm{T}-2$ and $\mathrm{T}+1$ will pick up the effects after 1 period; and estimates based on the change between period T-3 and T will pick up the immediate effects of the reform. Estimates based on stacked 3-year changes would therefore, at best, pick up an average of responses over 0 to 2 periods.

If there are multiple reforms, however, estimation may be confounded. To see this consider a tax increase in period $\mathrm{T}$ that is followed by a larger tax decrease in period $\mathrm{T}+2$. Changes in earnings (or hours) between period $\mathrm{T}-1$ and $\mathrm{T}+2$ will pick up the effects of the period $\mathrm{T}$ tax increase after 2 periods, and the immediate effects of the period $\mathrm{T}+2$ tax decrease. However, the entire change will be attributed to the net tax decrease between periods $\mathrm{T}-1$ and $\mathrm{T}+2$. In such circumstances, estimated elasticities would not represent even an average of shorter- and longer- run responses.

Thus, rather than adopt this approach, in this paper we instead include lagged changes in marginal and average tax rates as regressors. We estimate regressions of the form:

$$
\begin{gathered}
\Delta \ln Z_{i, t}=\alpha_{Z}+\sum_{n=0}^{1}\left(\beta_{Z, \tau}^{R, n} \Delta \ln \tau_{i, t-n}^{R}+\beta_{Z, \tau}^{E, n} \Delta \ln \tau_{i, t-n}^{E}+\beta_{Z, \rho}^{R, n} \Delta \ln \rho_{i, t-n}^{R}\left|+\beta_{Z, \rho}^{E, n} \Delta \ln \rho_{i, t-n}^{E}\right|\right)+ \\
\gamma_{Z} X_{i, t}+\varepsilon_{i, t, Z}
\end{gathered}
$$

In this example, $\beta_{Z, \tau}^{R, 0}$ picks up the short-run effect of changes in the net-of-marginal employer NICs rate between period t-1 and t on the changes in labour cost, Z, between period t- 1 and t. $\beta_{Z, \tau}^{R, 1}$ picks up the effect of changes in the net-of-marginal employer NICs rate between period $\mathrm{t}-2$ and $\mathrm{t}-1$ on the changes in labour cost, $\mathrm{Z}$, between period $\mathrm{t}-1$ and $t$, on top of any initial impact on labour cost, $\mathrm{Z}$, between period $\mathrm{t}-2$ and $\mathrm{t}-1$. Thus the effects of tax changes after two periods (approximately 12-18 months) can be calculated by adding the coefficients on the contemporaneous and lagged changes in tax rates (e.g. $\beta_{Z, \tau}^{R, 0}+\beta_{Z, \tau}^{R, 1}$ ).

As with contemporaneous changes in tax rates, it is important to instrument $\Delta l n \tau_{i, t-n}$ and $\Delta \ln \rho_{i, t-n} \mid$ appropriately. We do this using instruments based on earnings held fixed in period $\mathrm{t}-\mathrm{n}-1$ (i.e. setting the lag $\mathrm{k}=1$ ) as in our basic specification examining short-run responses. We again test the robustness of results to using instruments based on earnings held fixed at period t-n-2 levels. 


\section{Data}

The data used to estimate these regressions come from the New Earnings Survey Panel Dataset (NESPD), a mandatory survey of employers' payroll records collecting data on employees' earnings and basic characteristics for a pay period each April. ${ }^{16}$ The target sample frame of the NESPD is civilian employees in Great Britain whose National Insurance (NI) number ends with a specific pair of digits. Since the last digits of NI numbers are allocated randomly to all adults and the NESPD sample uses the same pair of digits each year, in principle this should deliver a random 1\% panel sample of employees; and since we have data from 1978 to 2015, we can follow the same individuals in any year in which they are employed (including if they change employer or region, say) for up to 38 years - a period during which there was a great deal of reform to the NICs schedule, as we describe in Section 2. In practice, despite the survey supposedly being mandatory, non-response reduces the sample to around $0.7 \%$ of employees on average over the period. Nevertheless, at around 165,000 individuals per year the NESPD contains a much larger sample than is available in other datasets of hours and earnings (such as the Labour Force Survey and the Family Resources Survey) and does not suffer from the same degree of measurement error, as responses are provided by employers with reference to their payroll and employment records.

We do not observe people when they are not employed, and cannot distinguish whether an employee who is absent from a particular year of data was not working, was selfemployed, or was working for an employer who failed to respond to the survey. Our estimation uses only people who we observe in employment in five successive waves of the NESPD (though not necessarily in the same job, or even in employment throughout the year in between waves), so that we can use a consistent sample for each regression specification we estimate. ${ }^{17}$ Thus the estimates of labour cost and hours responsiveness to NICs we obtain exclude standard extensive margin responses and are representative of intensive margin responses for those individuals observed continuously for at least 5 years (whose behaviour may differ somewhat to the rest of the population). The achieved sample size in each set of regressions is nearly 1.7 million, which is approximately $30 \%$ of the overall NESPD sample for the years in question.

\section{Key variables}

The main earnings variable recorded in the NESPD measures total cash earnings (including pay for overtime, commission, performance-related pay, etc.) for a particular pay period (typically a week or month, but in all cases converted to a weekly equivalent by the data provider). It excludes benefits in kind and employer (but not employee)

\footnotetext{
${ }^{16}$ The NESPD is in fact the result of joining together the old New Earnings Survey and the similar Annual Survey of Hours and Earnings which replaced it from 2004.

${ }^{17}$ Using our standard instrument (based on period $t-2$ income), we would need 3 waves $(t, t-1, t-2)$ for regressions including only contemporaneous changes in NICs rates, and 4 waves $(t, t-1, t-2, t-3)$ for those also containing lagged changes in NICs rates. When using our variant instrument (based on period $t-3$ income), five waves $(t, t-1, t-2, t-3, t-4)$ would be required for regressions containing lagged changes in NICs rates.
} 
pension contributions. This corresponds closely to the tax base for NICs, which is levied on a similar definition of earnings and is charged separately in each pay period. Thus the behavioural parameters we estimate are close to true taxable earnings elasticities for NICs purposes, and the elasticities capture all the corresponding behavioural responses: not only labour supply and demand but also shifting to make more/less use of forms of remuneration such as employer pension contributions which are not subject to NICs. ${ }^{18}$

The survey also includes compatible measures of hours of work (including and excluding overtime, etc.). Hourly wages are derived by dividing earnings by hours of work, which creates some potential division bias insofar as hours are measured with error (there should be little measurement error in earnings as they come from employers' payroll records).

\section{Calculating tax rates}

The principal independent variables of interest for our analysis are functions of people's marginal and average NICs rates. Since the NESPD measures the tax base - gross earnings - well (see above), we can essentially apply the relevant year's rate schedule to that tax base to calculate marginal and average rates of NICs. ${ }^{19}$

Note that we calculate NICs rates, not overall tax rates. The elasticities we calculate are therefore elasticities with respect to net-of-NICs rates, not net of the overall tax wedge. From 1990 onwards it would, in principle, be possible to approximate the income tax rates individuals' face on their earnings. However, since most of the biggest reforms to NICs happened in the 1980s, restricting attention to the post-1990 period would sacrifice much of our variation, making identification difficult. Before 1990 income tax in the UK was assessed on married couples' joint income (albeit with an option to elect to be taxed separately, with some loss of allowance); since we do not observe whether the employee is married, or the income of any spouse, we cannot account for this in our analysis, so cannot model income tax. Similarly, means-tested benefits and tax credits may also contribute to the effective tax wedge on an individual's earnings, but such entitlements always depend on couples' joint income and other characteristics (such as housing costs and the number and presence of children) that are not observed in our data, so we cannot account for those components of the tax wedge. Ignoring income tax and means-tested support will chiefly be a problem for our estimation if changes to these other elements of the tax wedge were correlated with changes to the NICs schedule, much like other omitted influences on earnings can confound our estimates if they are correlated with changes in NICs.

\footnotetext{
${ }^{18}$ One slight wrinkle to this relates to benefits in kind, which we discuss further in the Appendix A.

${ }^{19}$ Appendix A discusses cases where the tax rates we calculate may differ from those actually faced by employees and employers.
} 


\section{Timing}

One feature of the data which complicates our analysis is the proximity of the earnings we observe to the turn of the fiscal year. This means that we typically observe earnings at a time very near changes in NICs rates, and we cannot even be certain which NICs schedule applies to the earnings in question.

The fiscal year in the UK runs from 6 April to 5 April, and changes in NICs rates and thresholds usually take effect at the start of the fiscal year (though not always: two of the biggest reforms, in 1985 and 1989, took effect in October). The NESPD collects information each year about earnings and hours of work in the particular pay period that includes the 'survey reference date', a specific date in April. The precise date varies from year to year, ranging from 4 April to 29 April.

Earnings in respect of the pay period containing a particular date in April may be paid before or after 6 April, so we cannot be certain which fiscal year's NICs schedule applies to the earnings in our data. For example, suppose the employee's pay period is the calendar month and the employer therefore records their April earnings in the survey. If the employee is paid on the first day of each month then those April earnings will be subject to the NICs schedule for the old fiscal year (ending on 5 April), whereas if they are paid on the $15^{\text {th }}$ day or the last day of each month then their April earnings will be subject to the NICs schedule for the new fiscal year (starting on 6 April). Similar ambiguities can arise for employees with other pay periods, depending on the relationship between the survey reference date, the lengths and dates of pay periods, and the point in the pay period at which earnings are actually paid.

For the large majority of observations in our dataset, the earnings we observe will be subject to the NICs schedule of the fiscal year just beginning, but this will not be the case for all observations (particularly in years when the survey reference date is near the start of April) and we cannot identify those for which it is not true.

In what follows we proceed as if the earnings we observe are subject to the NICs schedule of the fiscal year just beginning. Under that assumption, we are typically estimating very short-run responses to changes in NICs rates - the effect on earnings of reforms implemented earlier in the same month - although note that (i) two of the biggest reforms to the NICs schedule (in 1985 and 1989) were implemented in October, not April, so a significant part of our identifying variation comes from reforms implemented around six months before the earnings outcomes we observe, and (ii) changes to the NICs schedule are invariably announced at least a few months in advance (so that payroll software can be ready in time to operate it, among other reasons), ${ }^{20}$ so

\footnotetext{
${ }^{20}$ This is different from income tax, for example, where rates are sometimes changed at short notice - and occasionally even retrospectively - because income tax operates annually and so incorrect tax deductions early in the fiscal year can be rectified by adjusting the amount of tax deducted later on in the fiscal year.
} 
we are estimating the effect on earnings of reforms announced some time beforehand. ${ }^{21}$ In those cases where the earnings we observe are in fact subject to the NICs schedule of the fiscal year just ending, our estimates will capture only earnings responses in anticipation of a reform's implementation, and the reform's implementation will instead be reflected in the subsequent year's earnings.

The timing of observed earnings relative to the announcement and implementation of reforms is thus worth bearing in mind for the interpretation of our results, and makes our estimates for the second year following a reform (using lagged changes in tax rates on earnings, as discussed in the preceding section), particularly pertinent.

\section{Descriptive statistics and results}

\section{Descriptive statistics}

Our final estimation sample consists of 1,696,200 observations. Table 3 shows that the basic characteristics of this sample. Men make up just under 6-in-10, those aged 50 or over make up 3-in-10 and those working in the public sector in both periods $\mathrm{t}-1$ and $\mathrm{t}$ make up 1-in-3 of the estimation sample. This sample is therefore somewhat more male, older and more likely to be in the public sector than the full NESPD sample. This reflects the fact that individuals with these characteristics are more likely to be observed for the requisite number of periods. Men, for instance, are less likely to move in and out of work, and to have the very low levels of earnings that mean they may not be sampled even if working (Blundell et al (2007)).

Table 3. Estimation sample descriptives

\begin{tabular}{lcc}
\hline & $\mathrm{N}$ & $\%$ \\
\hline Male & 982,754 & 58 \\
Female & 713,446 & 42 \\
& & \\
Aged $<50$ & $1,194,788$ & 70 \\
Aged $\geq 50$ & 501,412 & 30 \\
Public Sector & 560,461 & 33 \\
Private Sector & $1,015,588$ & 60 \\
Changed Sector & 120,151 & 7 \\
& & \\
Total Sample & $1,696,200$ & 100 \\
\hline Source: Authors' analysis using estimation sub-sample NESPD.
\end{tabular}

Source: Authors' analysis using estimation sub-sample, NESPD.

\footnotetext{
${ }^{21}$ Of course, when changes were announced (or expected) more than a year in advance, as occasionally happened, it is possible that our base period ('pre-reform') earnings might have responded in anticipation.
} 
Turning to our identifying variation in NICs rates, as discussed in Section 2 there were significant reforms to NICs in 1985, 1989 and between 1998 and 2000. Figures 2 to 7 show the (log) changes in the average and marginal net-of-NICs rates for employees and employers between 1985 and 1986 (Figures 2 and 3), between 1989 and 1990 (Figures 4 and 5) and between 1998 and 1999 (Figures 6 and 7). Overlaid on these NICs-change schedules are histograms showing the density of the earnings distributions.

Figure 2, for instance, shows that that changes in employee NICs rates in 1985 were towards the bottom of the earnings distribution, although sufficiently far up for there to be significant sample sizes. It also shows that marginal and average employee NICs rates changed in almost exactly the same way, with the exception of an increase in marginal NICs rate for a narrow range of earnings around $£ 265$ per week, associated with the UEL increasing slightly faster than average earnings growth. Figure 3 shows a similar picture for employer NICs for the bottom half of the earnings distribution although changes in these extended further up the earnings distribution (4 stepped rates of employer NICs were introduced during these reforms, as opposed to 3 stepped rates of employee NICs). The extension of full employer NICs above the UEL leads to a large discrete fall in the marginal net-of-NICs rate, and increases in the average net-ofNICs rate that smoothly increase above this point. Changes in net-of-NICs rates are also of a reasonable magnitude: increasing by up to approximately $5 \%$ and decreasing by up to approximately $10 \%$.

Figures 4 and 5 likewise show the effect of the 1989 reform, which provides significant independent variation in average and marginal rates of employee NICs, while Figures 6 and 7 illustrate the variation in average and marginal rates of employer NICs from the 1998 reform. Each of these reforms can thus make a significant contribution to disentangling the effects of different elements of the NICs regime.

In isolation, however, because the 1985 reforms affected employee and employer, and average and marginal NICs rates very similarly (except towards the very top of the earnings distribution), and because the 1989 and 1998 reforms significantly impacted only one of employee or employer NICs, it is not possible to use a single reform to identify the separate effects of changes in both average and marginal rates of both employee and employer NICs. Furthermore, as shown in Figures 8 to 10, mean reversion in earnings is a significant issue when estimating the impact of reforms to NICs that affect those with low earnings.

Figure 8, for instance compares the labour cost of two groups of employees (normalised by deflating labour cost in each year by the average earnings index and setting equal to 100 for both groups 1985): those whose earnings were $£ 32-£ 36$ in 1985, and those whose earnings were $£ 40-£ 44$ in 1985 . The latter range of income was subject to a 
Figure 2. Employee rate change, 1985-1986

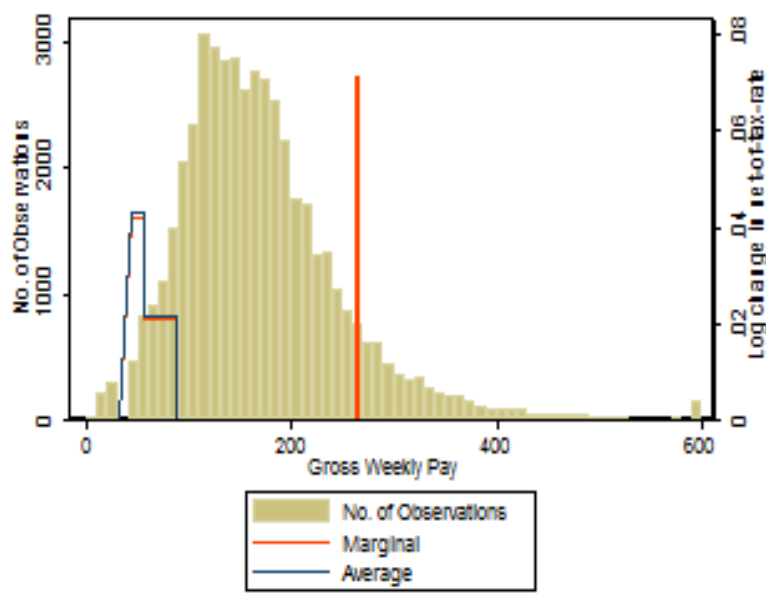

Figure 4. Employee rate change, 1989-1990

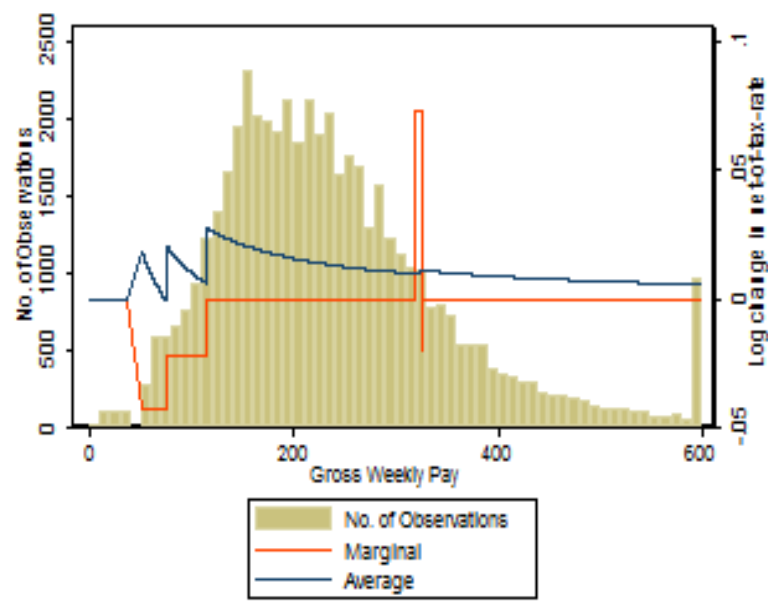

Figure 6. Employee rate change, 1998-1999

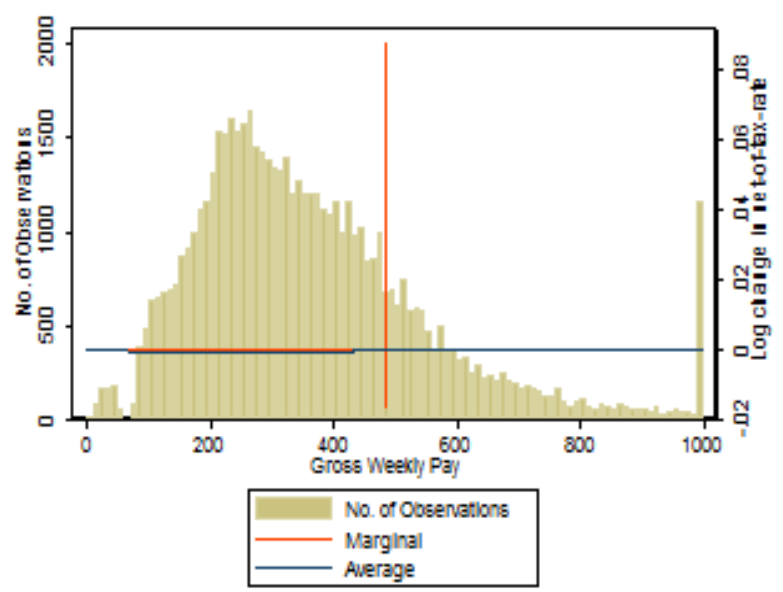

Figure 3. Employer rate change, 1985-1986

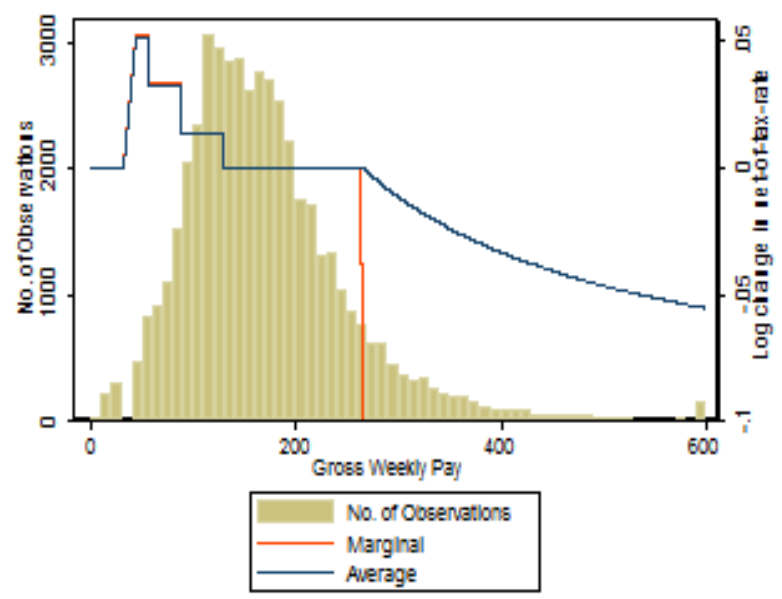

Figure 5. Employer rate change, 1989-1990

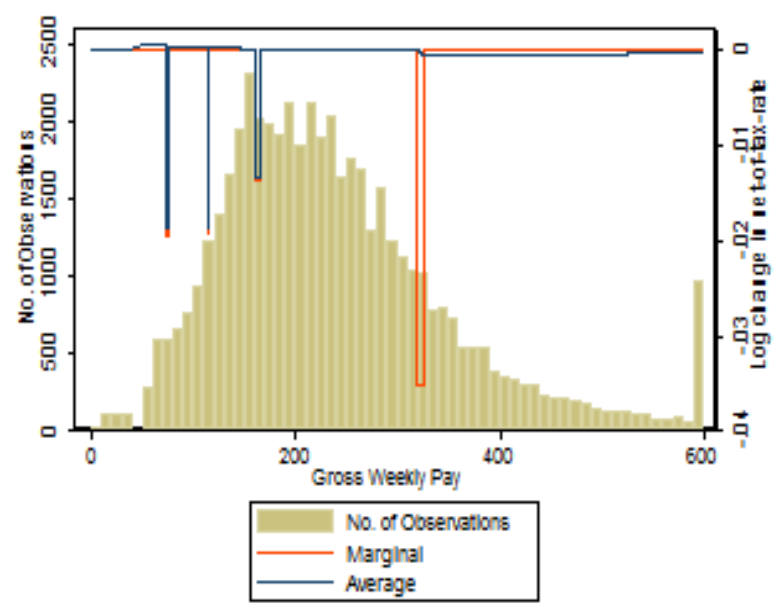

Figure 7. Employer rate change, 1998-1999

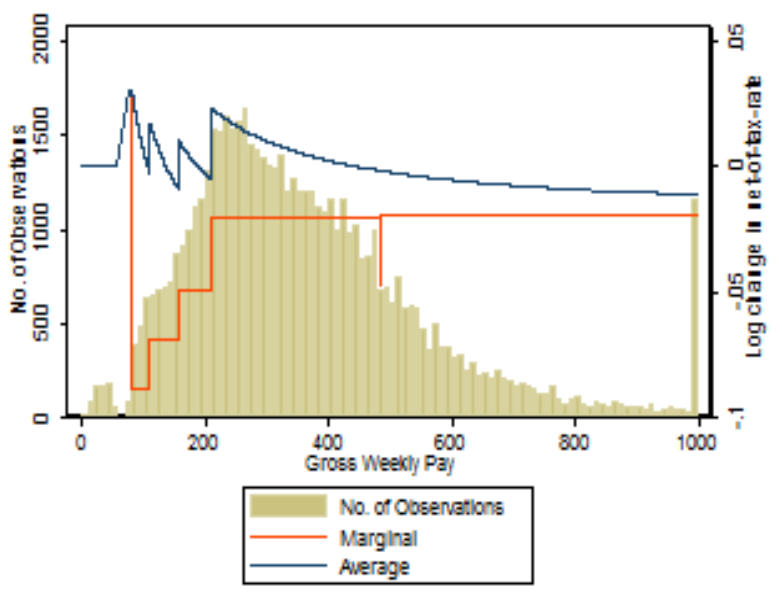


reduction in the marginal and average rates of employee and employer NICs in 1986,22 while the former was not subject to NICs in either 1985 or 1986 (it was and remained below the LEL). A naive difference-in-difference style analysis of this reform would attribute the relatively slower growth in the labour cost of the $£ 40-£ 44$ group following the reform to the reduction in NICs that this group likely faced, implying the (over)shifting of NICs to employers and/or very large income effects. But labour cost trends for the two groups were different prior to the reforms as well: the normalised labour costs of those in the $£ 40$-44 group had fallen considerably less between 1980 and 1985, than those in the $£ 32-36$ group. The pattern observed is therefore likely to reflect mean reversion, with the earnings of those in the $£ 32-36$ (more) temporarily depressed than those in the $£ 40$-44 group, and therefore growing more quickly in the subsequent years. Figures 9 and 10 show similar (albeit less stark) issues at the next NICs thresholds introduced in the 1985 reforms. ${ }^{23}$ The use of multiple years of data and multiple reforms both increasing and decreasing NICs in our full panel estimates allows us to address mean reversion more satisfactorily than for a single reform. As discussed in Kleven and Schultz (2014), having reforms that both increase and decrease rates of a tax on a given part of the income/earnings distribution should make mean reversion somewhat less problematic (as its effects work in opposite directions for tax increases and decreases).

\section{Figure 8. Normalised employer-cost between 1980 and 1989 for groups with earnings of $€ 32-£ 36$ and $€ 40-£ 44$ per week, respectively, in 1985}

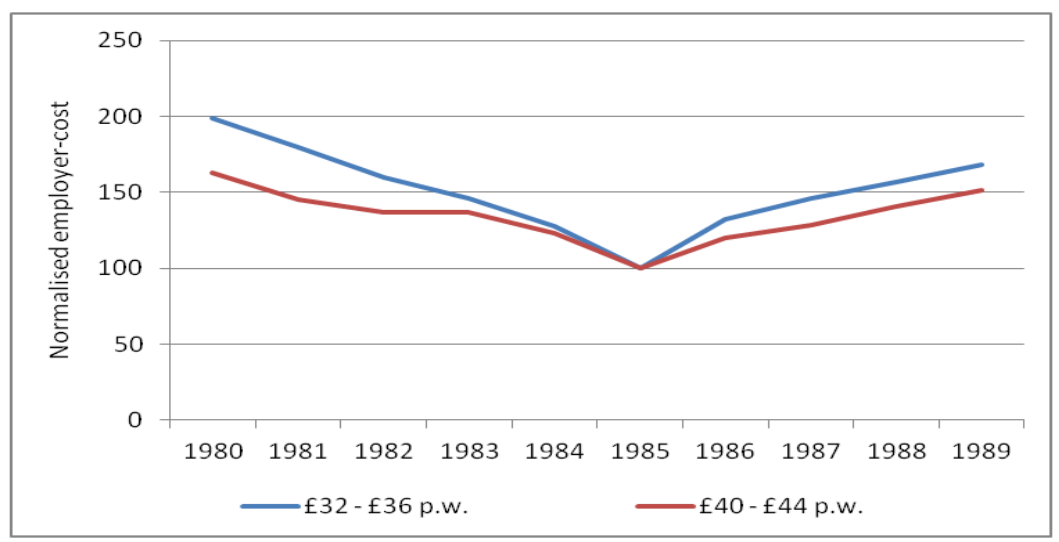

Source: Authors' calculations using NESPD.

\footnotetext{
${ }^{22}$ The standard NICs rates changed from $9 \%$ to $5 \%$, and from $10.45 \%$ to $5 \%$, respectively, for employee and employer NICs. The contracted-out rebates remained unchanged at $2.15 \%$ and $4.1 \%$, respectively.

${ }^{23}$ Figure 8 shows differential growth in normalised labour cost for groups around the threshold where standard employee and employer NICs increased from 5\% to 7\% after the reform (rates were $9 \%$ and $10.45 \%$ respectively both sides of the threshold prior to the reform). Figure 3 relates to the threshold where employee and employer NICs increased from $7 \%$ to $9 \%$ after the reform (rates were $9 \%$ and $10.45 \%$ respectively both sides of the threshold prior to the reform). The contracted-out rebates remained unchanged at $2.15 \%$ and $4.1 \%$, respectively.
} 
Figure 9. Normalised employer-cost between 1980 and 1989 for groups with earnings of $€ 53-£ 58$ and $€ 62-£ 67$ per week, respectively, in 1985

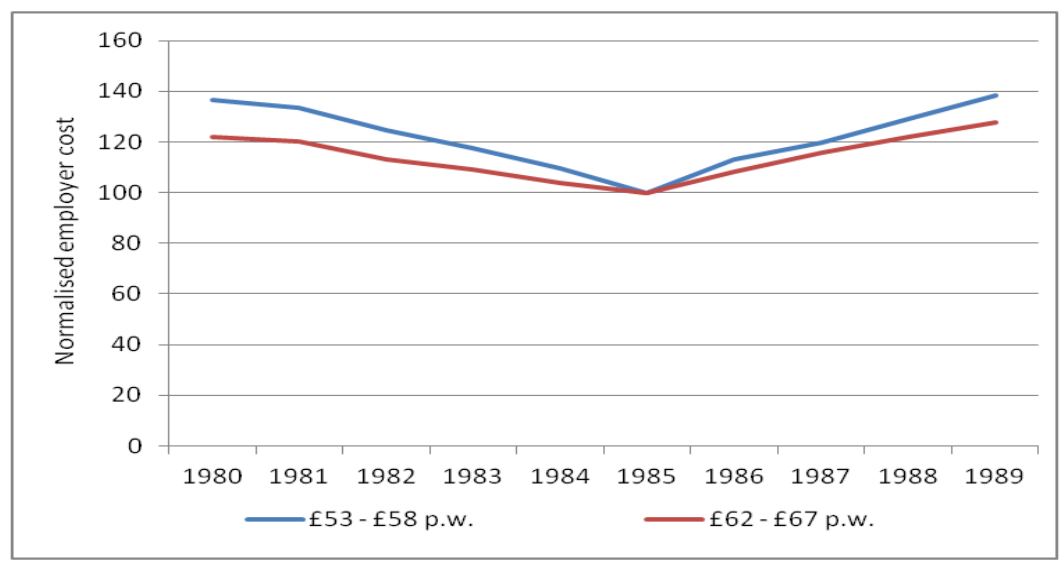

Source: Authors' calculations using NESPD.

Figure 10. Normalised employer-cost between 1980 and 1989 for groups with earnings of $£ 85-£ 92$ and $£ 98-£ 105$ per week, respectively, in 1985

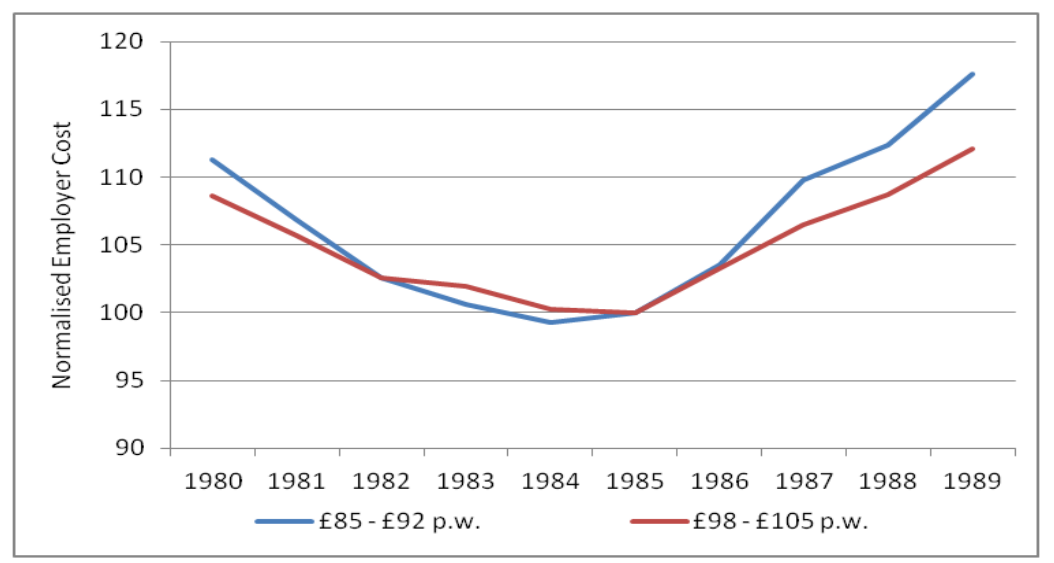

Source: Authors' calculations using NESPD.

We therefore turn to examining variation in tax rates using the full panel, covering reforms between 1982 and 2015. Tables 4 and 5 show the mean and standard deviation of (100 multiplied by) the changes in the log net-of-NICs rates, separately by position in the earnings distribution and by year.

Table 4 shows that over the period in question as a whole, marginal net-of-employeeNICs rates were reduced, especially in the lower-middle and middle part of the earnings distribution. This reflects increases in the statutory rates of NICs and reductions in the contracting-out-rebates - both of which reduce marginal net-of-employee NICs rates. Larger reductions in the marginal net-of-employer-NICs rates at the top of the earnings distribution reflect, in large part, the uncapping of employer NICs in October 1985. The abolition of the liabilities notches at the NICs LEL means that average net-of-NICs rates have been increased towards the bottom of the earnings distribution for employees, and a long way up the earnings distribution for employers (the uncapping of employer NICs 
means average net-of-employer-NICs rates have fallen at the very top of the distribution). Changes in marginal and average NICs rates over the last 30-or-so years therefore differ significantly, in principle allowing identification of the effects of both.

But our identification does not come simply from variation over the earnings distribution, or from the major reforms driving the patterns driving the broad patterns just described. The standard deviations of changes in log net-of-NICs rates for given parts of the earnings distributions are much larger than the mean changes, reflecting a pattern of increases and decreases in NICs rates at specific parts of the distribution in different years. Similarly, Table 5 shows significant variation in changes in log net-ofNICs rates for 
Table 4. Average annual change in log net-of-NICs rates by earnings quantile

\begin{tabular}{l|cc|cc|cc|ccc}
\hline Percentile & \multicolumn{2}{|c|}{ Marginal, employee } & \multicolumn{2}{|c|}{ Marginal, employer } & \multicolumn{2}{c|}{ Average, employee } & \multicolumn{2}{c}{ Average, employer } \\
& Mean & S.D & Mean & S.D & Mean & S.D & Mean & S.D \\
\hline $0-10$ & -0.029 & 1.610 & 0.019 & 2.098 & 0.090 & 0.680 & 0.206 & 0.754 \\
$10-25$ & -0.183 & 0.382 & -0.088 & 0.968 & 0.025 & 0.565 & 0.141 & 0.610 \\
$25-50$ & -0.183 & 0.365 & -0.055 & 0.569 & -0.037 & 0.451 & 0.103 & 0.438 \\
$50-75$ & -0.183 & 0.365 & -0.053 & 0.534 & -0.079 & 0.398 & 0.058 & 0.339 \\
$75-90$ & -0.117 & 2.278 & -0.127 & 1.157 & -0.098 & 0.392 & 0.024 & 0.354 \\
$90-100$ & -0.060 & 0.398 & -0.360 & 1.694 & -0.092 & 0.350 & -0.075 & 0.554 \\
\hline
\end{tabular}

Table 5. Average annual change in log net-of-NICs rates by year

\begin{tabular}{l|cc|cc|cc|ccc}
\hline Year & \multicolumn{2}{|c|}{ Marginal, employee } & \multicolumn{2}{c|}{ Marginal, employer } & \multicolumn{2}{c|}{ Average, employee } & \multicolumn{2}{c}{ Average, employer } \\
& Mean & S.D & Mean & S.D & Mean & S.D & \multicolumn{2}{c}{ Mean } & S.D \\
\hline 1983 & -0.499 & 0.488 & -0.094 & 0.489 & -0.490 & 0.068 & -0.131 & 0.025 \\
1984 & 0.001 & 0.092 & 0.414 & 0.173 & 0.011 & 0.005 & -0.079 & 0.128 \\
1985 & 0.036 & 0.510 & 0.858 & 0.544 & 0.026 & 0.024 & 1.350 & 0.147 \\
1986 & 0.258 & 0.851 & -0.461 & 3.557 & 0.256 & 0.808 & -0.058 & 0.033 \\
1987 & 0.098 & 0.869 & -0.057 & 0.485 & 0.041 & 0.179 & 0.464 & 0.059 \\
1988 & 0.070 & 1.316 & -0.446 & 0.723 & -0.071 & 0.283 & 0.934 & 0.115 \\
1989 & 0.104 & 0.887 & -0.082 & 0.469 & 0.045 & 0.110 & 0.440 & 1.489 \\
1990 & -0.154 & 1.144 & -0.080 & 0.442 & 1.410 & 0.533 & 0.024 & 0.171 \\
1991 & -0.142 & 1.006 & 0.158 & 0.548 & 0.022 & 0.095 & -0.282 & 0.354 \\
1992 & 0.115 & 0.908 & -0.108 & 0.524 & -0.003 & 0.061 & -0.008 & 0.203 \\
1993 & -0.167 & 0.227 & -0.613 & 0.353 & -0.154 & 0.031 & -0.028 & 0.233 \\
1994 & -0.854 & 0.539 & 0.358 & 0.385 & -0.781 & 0.154 & 0.068 & 0.264 \\
\hline
\end{tabular}




\begin{tabular}{|c|c|c|c|c|c|c|c|c|}
\hline 1995 & 0.021 & 0.425 & 0.133 & 0.332 & -0.009 & 0.012 & -0.045 & 0.292 \\
\hline 1996 & 0.031 & 0.518 & -0.037 & 0.344 & 0.024 & 0.014 & -0.548 & 0.191 \\
\hline 1997 & 0.135 & 1.067 & -0.001 & 0.624 & -0.008 & 0.074 & 0.364 & 0.365 \\
\hline 1998 & -0.160 & 0.275 & -0.097 & 0.492 & -0.169 & 0.033 & 0.142 & 0.297 \\
\hline 1999 & 0.036 & 0.558 & -2.746 & 1.724 & 0.000 & 0.022 & -0.037 & 0.298 \\
\hline 2000 & -0.092 & 1.364 & 0.021 & 0.683 & 0.724 & 0.518 & 0.051 & 0.523 \\
\hline 2001 & -0.051 & 1.269 & 0.283 & 0.495 & 0.204 & 0.180 & -0.087 & 0.479 \\
\hline 2002 & 0.110 & 1.144 & 0.389 & 0.641 & -0.030 & 0.109 & 0.412 & 0.864 \\
\hline 2003 & -1.036 & 0.692 & -0.916 & 0.541 & -0.809 & 0.195 & -0.066 & 0.064 \\
\hline 2004 & -0.034 & 0.649 & 0.019 & 0.367 & 0.002 & 0.026 & 0.146 & 0.097 \\
\hline 2005 & 0.073 & 0.978 & -0.045 & 0.570 & -0.024 & 0.070 & 0.306 & 0.124 \\
\hline 2006 & 0.074 & 0.845 & -0.029 & 0.377 & 0.004 & 0.052 & -0.736 & 0.167 \\
\hline 2007 & -0.017 & 0.401 & 0.141 & 0.262 & -0.018 & 0.009 & 0.013 & 0.009 \\
\hline 2008 & -0.484 & 2.066 & 0.198 & 0.850 & -0.087 & 0.276 & -0.056 & 0.030 \\
\hline 2009 & -0.351 & 2.033 & 0.002 & 0.716 & -0.006 & 0.247 & -0.022 & 0.016 \\
\hline 2010 & 0.011 & 0.643 & -0.028 & 0.418 & -0.022 & 0.028 & 0.116 & 0.039 \\
\hline 2011 & -0.612 & 2.295 & -0.620 & 1.925 & 0.146 & 0.602 & 0.090 & 0.092 \\
\hline 2012 & -0.118 & 0.978 & -0.131 & 1.153 & 0.042 & 0.123 & 0.065 & 0.059 \\
\hline 2013 & 0.186 & 1.468 & -0.002 & 0.642 & 0.070 & 0.109 & -0.038 & 0.022 \\
\hline 2014 & -0.016 & 1.180 & 0.066 & 0.970 & 0.098 & 0.090 & 0.115 & 0.601 \\
\hline 2015 & -0.057 & 0.749 & -0.002 & 0.480 & -0.039 & 0.020 & 0.014 & 0.146 \\
\hline
\end{tabular}

Source: Authors' calculations using NESPD.

Note: Values reported are 100 multiplied the change in the relevant log net-of-NICs rate. 


\section{Results}

Before separately estimating the effects of employee and employers' NICs, we first estimate the responsiveness of labour cost to the overall rate of NICs levied on an individual's earnings, using changes in tax rates between 1978 and 2010. The results of these regressions are shown in Table 6. Column 1 shows estimates where our set of controls $\boldsymbol{X}_{\boldsymbol{i}, \boldsymbol{t}}$ includes a cubic of $\ln Z_{i, t-2}$; column 2 shows estimates based on a quintic of $\ln Z_{i, t-2}$, and; column 3 shows estimates based on a 10 -piece spline of $\ln Z_{i, t-2}$. Estimated coefficients are broadly stable across specifications.

\section{Table 6. Estimated coefficient for regressions of $\Delta \ln Z_{i, t}$, overall NICs rate}

\begin{tabular}{lccc}
\hline & Cubic control & Quintic Control & Spline Control \\
\hline$\beta_{Z, \tau}$ & 0.099 & 0.089 & 0.104 \\
& $(0.0608)$ & $(0.0607)$ & $(0.0612)$ \\
$\beta_{Z, \rho}$ & $-1.051^{*}$ & $-1.042^{*}$ & $-1.077^{*}$ \\
\multirow{2}{*}{ No. of Observations } & $(0.0938)$ & $(0.0937)$ & $(0.0954)$ \\
& & $1,696,200$ & \\
\hline
\end{tabular}

Notes: ${ }^{*}$ Signifies a statistically significant difference from $0 .{ }^{\dagger}$ Signifies a statistically significant difference from -1 (for coefficients on net-of-average tax rates (1- $\rho$ ) only).

Estimates of $\beta_{Z, \tau}$ are positive, albeit small and not quite statistically significant. ${ }^{24}$ This would imply labour cost is therefore relatively unresponsive to compensated changes in marginal NICs rates, suggesting a relatively small deadweight loss of the tax. On the other hand, estimates of $\beta_{Z, \rho}$ are negative, large and highly statistically significantly different from 0 (but not from -1 ). These estimates can be interpreted in several ways. First, if one were to assume that the incidence of NICs were fully on employees, then this would imply very large, negative income effects. Alternatively, if one were to assume that income effects were small, then the estimates would imply that the incidence of NICs changes was effectively on employers. Finally, the results are consistent with moderate-to-large income effects and sharing of the burden of NICs between employees and employers.

Estimates based on the overall NICs rate include labour cost responses to both employee and employer NICs. But, particularly in the short term, the effects of employee and employer NICs could differ significantly. Table 7 shows coefficients estimated separately for employee and employer NICs.

Estimates of $\beta_{Z, \tau}^{E}$ are statistically significantly and positive (0.27), while estimates of $\beta_{Z, \tau}^{R}$ are near zero. These results are very similar to those found by Lehmann et al (2013) for France, where they found positive compensated elasticities for net-of-marginal

\footnotetext{
${ }^{24}$ Statistical significance is assessed at the $5 \%$ level throughout this article.
} 
income tax rates, and zero elasticities for employers' SSCs. Estimates of $\beta_{Z, \rho}^{E}$ are negative, of a moderate size, and statistically significantly different from 0 (and -1 ). This could be interpreted as evidence of some combination of moderately-sized income effects and the shifting of some incidence of employee NICs to employers. Estimates of $\beta_{Z, \rho}^{R}$ are also negative, but much larger in absolute magnitude. Indeed, the fact that they are statistically significantly greater than 1 in absolute magnitude is something of a puzzle. A coefficient of -1 would indicate full incidence of employer contributions on the employer. It might be natural to view $\beta_{Z, \rho}^{R}<-1$ as a combination of such statutory incidence with standard income effects. However, if employers are bearing the burden of employer contributions there is no change in earnings which can generate an income effect for the employee in question. We discuss this puzzle in greater detail below. However, while the exact figures differ, the broad pattern of results is consistent with those found by Lehmann et al (2013): evidence of behavioural response to marginal employee but not employer tax rates; and differences in responses to average tax rates that accord with differences in statutory tax incidence.

Table 7. Estimated coefficient for regressions of $\Delta \ln Z_{i, t}$, employee and employer NICs rates

\begin{tabular}{lccc}
\hline & Cubic control & Quintic Control & Spline Control \\
\hline$\beta_{Z, \tau}^{E}$ & $0.265^{*}$ & $0.267^{*}$ & $0.268^{*}$ \\
& $(0.1016)$ & $(0.1016)$ & $(0.1018)$ \\
$\beta_{Z, \tau}^{R}$ & 0.006 & -0.014 & 0.012 \\
& $(0.0689)$ & $(0.0688)$ & $(0.0695)$ \\
$\beta_{Z, \rho}^{E}$ & $-0.405^{*}$ & $-0.374^{*}$ & $-0.432^{*}$ \\
$\beta_{Z, \rho}^{R}$ & $(0.1696)$ & $(0.1692)$ & $(0.1708)$ \\
\multirow{2}{*}{ No. of Observations } & $-1.394^{*}+$ & $-1.396^{*}+$ & $-1.425^{*}$ \\
& $(0.1389)$ & $(0.1388)$ & $(0.1415)$ \\
\hline
\end{tabular}

Notes: ${ }^{*}$ Signifies a statistically significant difference from $0 .{ }^{\dagger}$ Signifies a statistically significant difference from -1 (for coefficients on net-of-average tax rates (1- $\rho$ ) only).

Of course, it is unsurprising that the effects of employee and employer NICs differ in the very short term: it may take time for wages to adjust to changes in tax rates. In the first column of Table 8, we therefore examine whether the effects of changes to NICs differ after an additional year(i.e. after 12-18 months rather than 0-6 months), by including changes in net-of-NICs rates lagged one year as regressors. Overall effects after this additional year can be obtained by adding the coefficient for the contemporaneous and lagged changes together (e.g. $\beta_{X, \tau}^{E, 0}+\beta_{X, \tau}^{E, 1}$ ).

Two things stand out. First, effects for contemporaneous changes are similar to those in Table 8: adding lagged changes in NICs rates does not affect the general pattern of 
results for contemporaneous changes - statutory incidence does appear to matter. The second thing to note is that while the coefficients on the lagged changes in net-ofmarginal and net-of-average NICs rates are sometimes statistically significant, so that effects of NICs changes differ after 12-18 months, there is no evidence of any equalisation of the behavioural effects and incidence of employee and employer NICs. For instance, the gap between the effect of average employee $\left(\beta_{X, \rho}^{E, 0}+\beta_{X, \rho}^{E, 1}\right)$ and average employer $\left(\beta_{X, \rho}^{R, 0}+\beta_{X, \rho}^{R, 1}\right)$ NICs rates grows, if anything, after 12-18 months, rather than shrinks (statistically speaking, we cannot reject the hypothesis that the gap remains unchanged).

Table 8 also includes estimated coefficients for regressions of $\Delta \ln (H)_{i, t}$ and $\Delta \ln (Z / H)_{i, t}$ on the same set of contemporaneous and lagged changes in net-of-NICs rates (columns 2 and 3). Looking first at hours of work, the coefficients on contemporaneous changes in NICs rates show a positive compensated hours-of-work elasticity for employee NICs of around 0.2 , and a statistically insignificant elasticity for employer NICs that is close to 0 . The coefficient on the net-of-average employee NICs rate indicates modest but statistically insignificant income effects. Taken at face value, the coefficient on the netof-average employer NICs rate would indicate much more substantial and statistically significant income effects.

As with labour cost, the coefficients on the lagged changes in net-of-NICs rates are, in three out of four cases, statistically significantly different from 0 : we can reject the effect of NICs on hours of work being the same after 12-18 months as after 0-6 months. However, in each instance the effects of lagged changes in tax rates reinforce the direction of effects of the contemporaneous effects. This means, for instance, that income effects would appear to be very large after 12-18 months.

Hourly labour costs do not respond to compensated changes in net-of-marginal rates in either the very short term or after 12-18 months. Turning to net-of-average NICs rates, the coefficient on employer NICs is close to -1 , while the coefficient on employee NICs is closer to 0 . This is strong evidence that statutory incidence matters for economic incidence in the immediate term. The modest but significantly negative coefficient on lagged net-of-average employer NICs means that, if anything, the difference in effects between employee and employer NICs grows over the year following a reform. In other words, the splitting of the statutory incidence of NICs between employers and employees continues to matter at least as much after 12-18 months as after 0-6 months. 
Table 8. Estimated coefficient for regressions of $\Delta \ln Z_{i, t}, \Delta \ln H_{i, t}$ and $\Delta \ln (Z / H)_{i, t}$, separate employee and employer NICs rates, and including changes in NICs rates lagged one period

\begin{tabular}{|c|c|c|c|c|c|c|}
\hline & \multicolumn{3}{|c|}{ Full sample } & \multicolumn{3}{|c|}{1982 - 1999 sample } \\
\hline & $\begin{array}{c}\Delta \ln Z_{i, t} \\
(1)\end{array}$ & $\begin{array}{c}\Delta \ln H_{i, t} \\
(2)\end{array}$ & $\begin{array}{c}\Delta \ln (Z / H)_{i, t} \\
\text { (3) }\end{array}$ & $\begin{array}{c}\Delta \ln Z_{i, t} \\
(4)\end{array}$ & $\begin{array}{c}\Delta \ln H_{i, t} \\
\text { (5) }\end{array}$ & $\begin{array}{c}\Delta \ln (Z / H)_{i, t} \\
\text { (6) }\end{array}$ \\
\hline$\beta_{X, \tau}^{E, 0}$ & $\begin{array}{c}0.135 \\
(0.1275)\end{array}$ & $\begin{array}{c}0.219 \\
(0.1003)\end{array}$ & $\begin{array}{c}-0.083 \\
(0.0952)\end{array}$ & $\begin{array}{c}0.792 \\
(0.2472)\end{array}$ & $\begin{array}{c}0.488 \\
(0.1652)\end{array}$ & $\begin{array}{c}0.301 \\
(0.1986)\end{array}$ \\
\hline$\beta_{X, \tau}^{R, 0}$ & $\begin{array}{c}-0.057 \\
(0.0741)\end{array}$ & $\begin{array}{c}0.02 \\
(0.059)\end{array}$ & $\begin{array}{c}-0.076 \\
(0.0535)\end{array}$ & $\begin{array}{c}0.049 \\
(0.0064)\end{array}$ & $\begin{array}{c}0.007 \\
(0.0426)\end{array}$ & $\begin{array}{c}0.046 \\
(0.0502)\end{array}$ \\
\hline$\beta_{X, \rho}^{E, 0}$ & $\begin{array}{c}-0.081 \\
(0.1941)\end{array}$ & $\begin{array}{l}-0.217 \\
(0.149)\end{array}$ & $\begin{array}{c}0.142 \\
(0.1417)\end{array}$ & $\begin{array}{c}-0.617^{*} \\
(0.2754)\end{array}$ & $\begin{array}{c}-0.468^{*} \\
(0.1857)\end{array}$ & $\begin{array}{c}-0.149 \\
(0.2152)\end{array}$ \\
\hline$\beta_{X, \rho}^{R, 0}$ & $\begin{array}{l}-1.524^{*} \dagger \\
(0.1432)\end{array}$ & $\begin{array}{c}-0.52^{* \dagger} \\
(0.1038)\end{array}$ & $\begin{array}{l}-1.001^{*} \\
(0.1099)\end{array}$ & $\begin{array}{l}-1.139^{*} \\
(0.1514)\end{array}$ & $\begin{array}{c}-0.076 \\
(0.0994)\end{array}$ & $\begin{array}{c}-1.065^{*} \\
(0.1211)\end{array}$ \\
\hline$\beta_{X, \tau}^{E, 1}$ (Lag) & $\begin{array}{c}0.186 \\
(0.1009)\end{array}$ & $\begin{array}{c}0.207^{*} \\
(0.0789)\end{array}$ & $\begin{array}{c}-0.021 \\
(0.0743)\end{array}$ & $\begin{array}{c}-0.577^{*} \\
(0.1542)\end{array}$ & $\begin{array}{c}-0.287^{*} \\
(0.1024)\end{array}$ & $\begin{array}{c}-0.289^{*} \\
(0.1225)\end{array}$ \\
\hline$\beta_{X, \tau}^{R, 1}(\mathrm{Lag})$ & $\begin{array}{c}0.13 \\
(0.0779)\end{array}$ & $\begin{array}{c}0.044 \\
(0.0616)\end{array}$ & $\begin{array}{c}0.086 \\
(0.0555)\end{array}$ & $\begin{array}{c}-0.126 \\
(0.0818)\end{array}$ & $\begin{array}{c}-0.107 \\
(0.0517)\end{array}$ & $\begin{array}{l}-0.019 \\
(0.065)\end{array}$ \\
\hline$\beta_{X, \rho}^{E, 1}(\mathrm{Lag})$ & $\begin{array}{c}-0.376^{*} \\
(0.1587)\end{array}$ & $\begin{array}{c}-0.278^{*} \\
(0.1169)\end{array}$ & $\begin{array}{c}-0.106 \\
(0.1183)\end{array}$ & $\begin{array}{c}0.369 \\
(0.246)\end{array}$ & $\begin{array}{c}0.095 \\
(0.1629)\end{array}$ & $\begin{array}{c}0.279 \\
(0.1941)\end{array}$ \\
\hline$\beta_{X, \rho}^{R, 1}(\mathrm{Lag})$ & $\begin{array}{l}-0.572^{*} \dagger \\
(0.1509)\end{array}$ & $\begin{array}{c}-0.33^{*} \dagger \\
(0.1095)\end{array}$ & $\begin{array}{l}-0.234^{*} \dagger \\
(0.1141)\end{array}$ & $\begin{array}{c}0.006 \\
(0.2335)\end{array}$ & $\begin{array}{c}0.103 \\
(0.1503)\end{array}$ & $\begin{array}{l}-0.098 \\
(0.186)\end{array}$ \\
\hline $\begin{array}{l}\text { No. of } \\
\text { Observations }\end{array}$ & & $1,696,20$ & & & 867,2 & \\
\hline
\end{tabular}

Notes: " Signifies a statistically significant difference from 0 (at the $5 \%$ level). ${ }^{\dagger}$ Signifies a statistically significant difference from - 1 (for coefficients on contemporaneous net-of-average tax rates (1- $\rho$ ) only) (at the $5 \%$ level).

Results are for quintic specification only.

Columns 4-6 repeat the analysis of columns 1-3 but for data covering the period between 1982 and 1999 only. We do this as a robustness check because 1999 saw the introduction of the National Minimum Wage, which put a floor below which employers were legally not allowed to reduce hourly wages (which may affect the incidence of NICs for low paid workers), and a significant expansion of in-work means-tested benefits (which may affect the labour market behaviour of low-paid workers more generally).

While specific coefficients differ, sometimes quite dramatically, between the full sample and the 1982-1999 sample, behavioural responses after 12-18 months (i.e.

incorporating lags) are broadly similar for the two groups. For instance, while the coefficient $\beta_{Z, \tau}^{E, 0}$ is much larger (0.792) for the 1982-1999 subsample than for the full 
sample (0.135), the overall effect after $12-18$ months (i.e. $\beta_{Z, \tau}^{E, 0}+\beta_{Z, \tau}^{E, 1}$ ) is much closer ( 0.215 versus 0.321$)$. Moreover, the effects of changes in net-of-average employer NICs on labour costs are very similar to those obtained for the full sample, suggesting that the introduction of the NMW did little to affect the overall incidence of employer NICs (at least across the earnings distribution as a whole).

The strangest results in Table 8 relate to net-of-average employer NICs rates $\left(\beta_{X, \rho}^{R, 0}\right.$ and $\beta_{X, \rho}^{R, 1}$ ). The hourly labour cost regressions in columns 3 and 6 show coefficients in the region of -1 , suggesting that incidence is fully on the employer: not surprising in the short run. But for the full sample the hours regression (column 2) shows a coefficient of -0.52 , becoming -0.85 after an additional year. These would represent implausibly large income effects even if incidence were on the employee. But if the incidence is fully on the employer, the employee's income does not change and there should be no such income effects. Why, then, should a reduction in the average employer NICs rate (controlling for the marginal rate, of course) cause employers to reduce their employees' hours of work? One possible reason suggests itself. Reducing average NICs rates while holding marginal NICs rates constant is an upward shift in the budget constraint, like giving firms an extra lump sum per worker. Given an extra lump sum per worker, presumably a natural response for firms is not only to hire more workers and produce more output, but also to produce any given amount of output with more workers and fewer hours per worker; we aren't looking at extensive margin responses, so all we see in our regression is reduced hours per worker in response to the lower average NICs rate. However, while this mechanism is possible, it is hard to believe it would be powerful enough to explain the size of the estimated coefficients. Stranger still, these large effects of average employer NICs rates disappear if we restrict attention to the 1982-99 period (column 5). It is hard to believe that this phenomenon arose powerfully after 1999 having been absent beforehand. Although far from certain, the likeliest explanation would seem to be that the result is driven by some omitted factor (perhaps a non-NICs reform or a macroeconomic shock) with a large effect on hours of work that is correlated with the variation in NICs rates that identifies the effect of average employer NICs changes (conditional on marginal employer NICs rates and average employee NICs rates) after 1999. For now, this result remains a puzzle within our broader findings.

Table B1 in our results appendix includes the same set of regressions, albeit based on instruments calculated using earnings held fixed in period t-3 (i.e. lagged by $\mathrm{k}=2$ periods). While the exact figures differ, the strongest findings in our preferred specification remain unaltered: the regressions suggest that the incidence of employer NICs remains on employers after 12-18 months; hours-of-work increase in response to reductions in marginal employee NICs rates, but not marginal employer NICs rates. Some other results differ, however. Most notably, in contrast to the main results, reductions in the marginal employee NICs rate reduce hourly labour cost after 12-18 
months, which is difficult to interpret either in terms of standard labour supply or demand responses. ${ }^{25}$

Results for further selected sub-samples using our standard specification can be found in Table B2 in our result appendix. Again, the clearest findings from analysis of the full sample hold: hours responses to changes in marginal employee rates are larger than marginal employer rates; and hourly labour cost responses to average employee and employer NICs rates suggest that statutory incidence generally matters for at least 1218 months following a reform. Furthermore, as one might expect, responses differ for workers in the public versus private sector. There is evidence, for instance, of responses to changes in marginal employee NICs rates occurring more quickly in the private sector than the public sector. There is also evidence, after 12-18 months, of some shifting of the burden of employee NICs to public sector but not private sector employers.

Other results are somewhat more unexpected though:

- Males are more responsive to changes in marginal employee NICs rates than females, which contrasts with typical findings (Meghir and Phillips (2010)). ${ }^{26}$

- While incidence is initially closer to statutory, employers seem to more than fully bear employer NICs for females and those aged over 50 after 12-18 months. In contrast, employees seem to more than fully bear employee NICs among the over 50s both immediately and after 12-18 months. Explaining such results is difficult, although over-shifting of tax burdens can occur in markets subject to imperfect competition (Fullerton and Metcalf (2002)).

\section{Conclusions}

In this paper we estimate the responses of labour cost, hours and labour cost per hour to marginal and average rates of employee and employer NICs in the UK, using reforms during the 1980s, 1990s and 2000s as our source of identifying variation. Previous evidence on the responsiveness of earnings to social security contributions is sparse, in contrast to the voluminous literature on the responses of taxable income to income tax; this paper helps to fill that gap. Furthermore, by considering responses in the context of both behavioural responses and the (intimately related) incidence of a tax, this paper attempts to help link the New Tax Responsiveness and incidence literatures. We investigate the very short-term effects using contemporaneous changes in NICs and the slightly longer-term effects using the change in NICs rates during the previous year. This is an improvement on the typical approach of using longer panel periods (e.g. 2 or 3 years rather than 1 ) in an attempt to examine such effects.

\footnotetext{
${ }^{25}$ Coefficients on net-of-marginal rates should be 0 or positive if substitution effects operate.

${ }^{26}$ Although the finding that income effects for employee NICs are larger for females than males is more in keeping with the literature.
} 
Our estimates show that responses to employee and employer NICs differ significantly both in the immediate period following implementation of a reform (0-6 months) and the slightly longer term (12-18 months). We find positive, statistically significant effects on labour cost, operating via hours of work, of reductions in marginal rates of employee NICs. We also find that labour cost falls more than one-for-one when average employer NICs rates are reduced, but by much less when employee NICs rates are reduced, with most of the effect (and nearly all of the discrepancy) operating via hourly labour cost. These differences are robust across specifications based on different instruments and different sets of controls for divergent earnings and hours trends.

Our interpretation of our overall findings is similar to Lehmann et al (2013), who find similar results for labour cost for France. That is, that there is wage stickiness that does not begin to abate for at least 12-18 months, so the economic incidence of NICs reflects its legal incidence during at least this period; that low-middle earners respond modestly (on the intensive margin) to employee NICs changes that directly affect them; and that if firms respond to higher labour costs at the margin, they do so via the extensive rather than the intensive margin. Consideration of the effects of average employee NICs rates on hours of work also suggests that income effects may be significant for the largely low-middle earners for whom our elasticities are estimated (most of the big reforms to NICs during this period affected low-middle earners, the uncapping of the UEL being the notable exception). We also find large positive effects of average employer NICs rates on hours of work, which is more puzzling since there should be no income effects if (as our labour cost regressions suggest) the short-run incidence of employer NICs changes is on firms; this result disappears if we restrict attention to the period before 1999. Subgroup analysis reveals the public sector experiencing slower behavioural responses to changes in marginal rates of employee NICs and more of the incidence being shifted to the employer, but also some surprising results, with substitution effects seemingly larger for men than women and some evidence of incidence being more than $100 \%$ on one side of the market for older workers. The main findings of the analysis, however, remain intact.

This work could be extended in several ways. First, one could extend the number of lagged changes in tax rates included to examine the effect of changes in NICs on labour cost and hours after longer time periods (for instance $24-30$ months with one additional lag, or 36 - 42 months with two). This would allow one to test whether, for instance, the effects of employee and employer NICs begin to equalise, and if so, over what time horizon. In order to do this, one would probably need to use instruments based on earnings from longer before the period in question (although this could weaken their statistical power). Second, one could extend analysis to consider the effects of income tax and of means-tested benefits and tax credits. The NESPD, on which this study is based, does not allow us to estimate the marginal and average tax rates associated with these parts of the tax and benefit system: they are assessed on broader, usually family-level, measures of income, rather than individual earnings. To do this, one would therefore need to make use in some way of alternative datasets (standard 
household surveys such as the Family Resources Survey, the Family Expenditure Survey and the British Household Panel Survey) which can provide information on these aspects but without all the other advantages of the NESPD.

\section{References}

Adam, S., J. Browne, D. Phillips and B. Roantree (2016), "Adjustment costs and labour supply: evidence from bunching at tax thresholds in the UK", Mimeo

Adam, S. and G. Loutzenhiser (2007), 'Integrating Income Tax and National Insurance: An Interim Report', IFS Working Paper no. W07/21, http://www.ifs.org.uk/publications/4101.

Anderson, P. M., and B. D. Meyer (1997), 'The effects of firm specific taxes and government mandate with an application to the US unemployment insurance program', Journal of Public Economics, Vol. 75, No. 2, pp 119 - 145

Anderson, P. M. and B. D. Meyer (2000), 'The effects of the unemployment insurance payroll tax on wages, employment, claims and denials', Journal of Public Economics, Vol. 78, pp. $119-145$

Atkinson, A.B., Micklewright, J. and Stern, N.H. (1981), 'A comparison of the FES and NES 1971-1977: Part I. Characteristics of the sample', Social Science Research Council Programme on Taxation, Incentives and the Distribution of Income Working Paper no. 27.

Atkinson, A.B., Micklewright, J. and Stern, N.H. (1982), 'A comparison of the FES and NES 1971-1977: Part II. Hours and earnings', Social Science Research Council Programme on Taxation, Incentives and the Distribution of Income Working Paper no. 32.

Auten and Caroll (1999), 'The effect of income tax on household income', The Review of Economics and Statistics, Vol. 81, No. 4, pp $681-693$

Bingley, P. and G. Lanot (2002), 'The Incidence of Income Tax on Wages and Labor Supply', Journal of Public Economics, Vol. 83, pp. 173 - 194

Blundell, R. and B. Etheridge (2010), 'Consumption, income and earnings inequality in Britain', Review of Economic Dynamics, Vol. 13, No. 1, p $76-102$

Blundell, R. and T. Macurdy (1999), 'Labor supply: A review of alternative approaches', Handbook of Labor Economics Vol. 3, Part A, O. C. Ashenfelter and D. Card (eds)

Bunel, M. and Y. L'Horty (2012), 'The effects of reduced social security contributions on employment: an evaluation of the 2003 French reforms', Fiscal Studies, Vol. 33, No. 3, pp. $371-398$

Chetty, R., A. Looney, and K. Kroft (2009), 'Salience and taxation: theory and evidence', The American Economic Review, Vol. 99, No. 4, pp. 1145 - 1177

Cotterell, B. (2007), 'Optimal sample size reduction for the Annual Survey of Hours and Earnings', Survey Methodology Bulletin No.61 - September 2007, Office for National 


\section{Statistics}

(http://webarchive.nationalarchives.gov.uk/20160105160709/http://www.ons.gov uk/ons/guide-method/method-quality/survey-methodology-bulletin/smb61/index.html).

CPB et al (2015), 'Study on the effects and incidence of labour taxation', Study for the European Commission

Devereux, P. J and Hart, R. A. (2010), 'Forced to be rich? Returns to compulsory schooling in Britain', The Economic Journal, 120 (December), 1345-1364

Diamond, P. and J. Mirrlees (1971), 'Optimal taxation and public production I and II', American Economic Review, Vol. 61, pp. 8 - 27 and pp. $261-278$

Disney, R., C. Emmerson and M. Wakefield (2008), 'Pension provision and retirement saving: lessons from the United Kingdom', Canadian Public Policy, Vol. 34, No. 1, 155 176.

European Commission (2013), "Study on the Impacts of Fiscal Devaluation", Working Paper No. 36-2013

European Commission (2015), "Study on the effects and incidence of labour taxation", Working Paper No. 56-2015

Feldstein, M. (1995), 'The Effect of Marginal Tax Rates on Taxable Income: A Panel Study of the 1986 Tax Reform Act', The Journal of Political Economy, Vol. 103, No. 3, pp. $551-572$

Feldstein, M. (1999), 'Tax Avoidance and the Deadweight Loss of the Income Tax', The Review of Economics and Statistics, Vol. 81, No. 4, pp. $674-680$

Fullerton, D. and G. E. Metcalf (2002), 'Tax incidence', Chapter 26, Handbook of Public Economics: Volume IV, A. Auerbach and M. Feldstein (eds)

Gruber, J. and E. Saez (2002), 'The elasticity of taxable income: evidence and implications', Journal of Public Economics, Vol. 84, pp 1 - 32

Hamermesh, D. (1996), Labor Demand.

Hood, A. and L. Oakley (2014a), 'A survey of the GB benefit system', IFS Briefing Note BN13, http://www.ifs.org.uk/publications/1718.

Hood, A. and L. Oakley (2014b), 'The social security system: long-term trends and recent changes', IFS Briefing Note BN156, http://www.ifs.org.uk/publications/7438.

Kleven, H., and E. Schultz (2014), 'Estimating taxable income responses using Danish Tax reforms', American Economic Journal: Economic Policy, Vol. 6, No. 4, pp 271-301

Kopczuk, W. (2005), 'Tax bases, tax rates and the elasticity of reported income', Journal of Public Economics, Vol. 89, No. 11-12, pp. 2093-2119

Kubik, J. D. (2004), 'The incidence of personal income taxation: evidence from the tax reform act of 1986', Journal of Public Economics, Vol. 88, pp. 1567 - 1588 
Lehmann, E., F. Marical, and L. Rioux (2013), 'Labor income responds differently to income-tax and payroll-tax reforms', Journal of Public Economics, Vol. 99, pp. 66 - 84

Leigh, A. (2010), 'Who Benefits from the Earned Income Tax Credit? Incidence among Recipients, Co-Workers and Firms', The B. E. Journal of Economic Analysis and Policy, Vol. 10, No. 1, Article 45

Lhommeau, B. and V. Remy (2009), 'Les politiques d'allgements ont-elles un effet sur la mobilite salariale des travailleurs a bas salaires', Economie et Statistique, Vol, 429 430, pp $21-49$

Meghir, C. And D. Phillips (2010), 'Labour supply and taxes', Chapter 3, 'Dimensions of Tax Design'. Adam, S. et al (eds)

Melguizo, A. and J. M. Gonzalez-Paramo (2013), 'Who bears labour taxes and social contributions? A meta-analysis approach', SERIEs, Vol. 4, No. 3, pp 274 - 271

Mirrlees, J., S. Adam, T. Besley, R. Blundell, S. Bond, R. Chote, M. Gammie, P. Johnson, G. Myles, and J. Poterba et al (2011), 'Tax by Design: The Mirrlees Review', Oxford: Oxford University Press for the Institute for Fiscal Studies, https://www.ifs.org.uk/publications/mirrleesreview.

Office of Tax Simplification (2015), 'Alignment of Income Tax and National Insurance: Terms of Reference', https://www.gov.uk/government/publications/ots-review-ofincome-tax-and-national-insurance-tor

Pissarides, C. (1998), 'The impact of employment tax cuts on unemployment and wages; The role of unemployment benefits and tax structure', European Economic Review, Vol. 42, pp. 155 - 183

Saez, E., J. Slemrod, and S. H. Giertz (2012), 'The Elasticity of Taxable Income with Respect to Marginal Tax Rates: A Critical Review', Journal of Economic Literature, Vol. 50, No. 1, pp 1-50

Saez, E., M. Matsaganis and P. Tsakloglou, 'Earnings determination and taxes: evidence from a cohort-based payroll tax reform in Greece', Quarterly Journal of Economics, Vol. 127, No. 1, pp 493 - 533

Summers, L. H. (1989), 'Some Simple Economics of Mandated Benefits', The American Economic Review, Vol. 79 No. 2, pp 177-83

Weber, C. (2014), 'Towards obtaining a consistent estimate of the elasticity of taxable income using differences-in-differences', Journal of Public Economics, Vol 117, pp. 90 $-103$ 


\section{Appendix A. Data}

The NESPD is supposed to be a random 1\% sample of the population, but in practice it includes only around $0.7 \%$ of employees on average over the period ( $1 \%$ of employees in Britain would be around 235,000 per year, not the 165,000 we actually observe). The main reason for this is that, despite supposedly being mandatory, the survey suffers from significant non-response. The valid response rate fell from over $75 \%$ in the 1980 s to around $60 \%$ by $2012 .{ }^{27}$ Non-response reduces sample size and therefore the precision of our estimates, though as noted above our sample remains large. More troubling is that non-response could lead to bias in our estimates if it is correlated with labour market behaviour. However, we note that non-response is typically at least as big a problem in these alternative household survey datasets.

In addition, there are a number of more minor reasons that our sample may not be completely random:

- As a cost-saving measure, the sample size was reduced by $20 \%$ in 2007 and 2008 before being restored in 2009. This reduction was not random but restricted to those employers - typically smaller ones - who completed the survey on paper rather than electronically (in order to maximise the saving in compliance effort for respondents) and concentrated in industries where earnings were less variable (in order to minimise the resulting increase in the coefficient of variation of earnings). ${ }^{28}$ However, since the reduction applied in only two of the 38 years of our data, and those were not years of significant reform generating the variation we exploit, we do not believe this should significantly affect our overall estimation.

- There is potential for under-sampling of the employees with the lowest earnings. Specifically, those earning below the LEL (the earnings level at which NICs became payable, until the late 1990s - since then the NICs exemption level has been higher than the LEL). This is because employees are identified for inclusion in the NESPD using data from PAYE (Pay As You Earn), the UK's system for deduction of income tax at source by employers, and employers are only required to include those earning above the LEL in their PAYE scheme. However, this does not appear to be a significant problem in practice: employers seem to register all their employees on their PAYE scheme, even those they are not obliged to include. When we compare the distribution of earnings above and below the LEL in the NESPD data with those in other datasets that do not suffer from the same potential selection issues, we find that the two densities look broadly similar. ${ }^{29}$

\footnotetext{
${ }^{27}$ Source: authors' correspondence with the Office for National Statistics.

${ }^{28}$ See Cotterell (2007) for details.

${ }^{29}$ We compared the NESPD with the Family Resources Survey and found no difference. Devereux and Hart (2010) compared the NESPD with the (smaller and less reliable but longer-running) General Household Survey and did find a somewhat lower proportion of observations were below the LEL in the NESPD than in the GHS
} 
- Before 2004, the NESPD sample was identified exclusively from PAYE records taken between January and March, and so excluded people starting a new job (whether previously working elsewhere or not working) between then and the survey reference date in April. Since 2004 this problem has been eliminated by taking a second, supplementary extract of PAYE records in April to pick up any employees missing from the initial sample. But for years before 2004 our data exclude employees starting a new job in the few weeks before the reference date in April.

- Since 2005, employees have been removed from the dataset if their earnings were below $£ 10,000$ per year ( $£ 11,000$ since 2009 ) and either (a) their job title was 'Director', (b) they had the same first initial and surname as the employer completing the survey, (c) they 'fail the automated National Minimum Wage check' or (d) their earnings were an outlier for their occupation. ${ }^{30}$ This is an attempt to identify and remove company owner-managers who are manipulating their earnings - for example, taking dividends instead to reduce their tax liability - and are therefore perceived to be producing a distorted picture of the earnings distribution (though in practice these criteria may remove some other employees as well). However, for our purposes, such income shifting may be one of the kinds of response to taxation we might like to capture, and this procedure means that from 2005 onwards our estimation excludes these responses and this small but potentially highly responsive group.

The key variables in our data are earnings and hours of work. Item non-response is low. Before 2004 observations with missing earnings were removed from the dataset (and are included in the survey non-response rate discussed above), and we also remove observations with missing hours (between 4\% and 12\% of observations). Since 2004 missing values have been imputed (and such cases are not identified), but the number of such cases is small: around $0.5 \%$ of observations have missing earnings imputed and the figure for hours is just over $1 \%$.

The measure of earnings in our data corresponds closely to the definition of taxable earnings for NICs purposes. But one slight wrinkle relates to benefits in kind:

\footnotetext{
(18\% vs. $27 \%$ among women). Devereux and Hart (2010) also report that 'Atkinson et al. (1981, 1982) have compared the NESPD to a household survey, the Family Expenditure Survey, and found that the two surveys were fairly consistent in their hours and earnings patterns.' Looking within the NESPD, the Office for National Statistics report that there was little change in the observed earnings distribution in 2014 when the PAYE sampling frame moved to 'Real-Time Information' and larger employers were required to include all of their employees, not just those above the LEL, though any under-sampling was likely to be concentrated in smaller firms anyway.

${ }^{30}$ Source: Authors' correspondence with the Office for National Statistics. It is not clear exactly what the 'automated National Minimum Wage check' entails, since we do observe people in our data receiving less than the national minimum wage. Nor is it clear what constitutes an 'outlier' for these purposes.
} 
- Some things we might think of as benefits in kind (broadly those that can be exchanged for cash or are equivalent to cash, such as goods or services bought by the employee but paid for by the employer) are treated like cash in tax law and subject to NICs in full. It is difficult to know whether employers are including those things when they provide earnings measure in the NESPD; if they are not then our earnings measure underestimates taxable earnings. Note that this need not bias our estimates unless these taxable benefits respond more or less to changes in NICs rates than cash earnings do.

- Other benefits in kind - the principal ones being company cars and fuel and private medical insurance - were not subject to NICs at all until the 1990s. But the NICs base was gradually broadened to bring more benefits in kind within the scope of employer NICs (employer NICs were applied to company cars and fuel from 1991, and to most other benefits in kind from 2000),31 though these benefits in kind remain outside the scope of employee NICs. Thus from 1991 our earnings measure will be a slight underestimate of low-paid workers' earnings for employer NICs purposes (though not for employee NICs purposes). As with any other reforms or economic shocks, these extensions to the NICs base can confound our estimation if they are correlated with the changes to NICs rates on which our estimates are based. ${ }^{32}$ However, since these benefits in kind account for only a very small fraction of total remuneration, we do not expect the effect on our estimation to be large.

While NICs liability depends primarily on earnings as measured well in the NESPD, it can also depend on other variables not recorded in the NESPD. One such issue is the ability of individuals to 'contract out' from the state second pension and thereby pay a lower rate of NICs. As discussed in Section 2 of the main text, we do not observe this decision but treat all individuals as contracted out. Perhaps more problematically, a special 'married women's reduced rate' of employee NICs - 2\% at the start of our period, rising to $5.85 \%$ by the end - was (and remains) available, in exchange for reduced benefit entitlements, to married women who have been claiming it almost continuously since May 1977. This applied to a substantial number of women in the 1980s, but almost none by the end of the period. Since we cannot identify married women in the NESPD, let alone those choosing this option, we ignore it.

\footnotetext{
${ }^{31}$ Except for employees earning less than $£ 8,500$ per year, for whom benefits in kind remained outside the scope of NICs - and indeed income tax - until April 2016.

32 In fact 1991 saw a small reduction in employer NICs rates, and 2000 an increase in the earnings level at which employee NICs became payable, so if (say) employers reduced employees' earnings in those years to pass on the cost of the extension of employer NICs to more benefits in kind then we will be wrongly attributing those earnings reductions to the effects of the changes in NICs rates that happened in those years.
} 


\section{Appendix B. Additional Estimates}

Table B1. Estimated coefficient for regressions of $\Delta \ln Z_{i, t}, \Delta \ln H_{i, t}$ and $\Delta \ln (Z / H)_{i, t}$, separate employee and employer NICs rates, and including changes in NICs rates lagged one period, alternative instrument

\begin{tabular}{|c|c|c|c|}
\hline & $\begin{array}{c}\Delta \ln Z_{i, t} \\
(1)\end{array}$ & $\begin{array}{c}\text { Full sam } \\
\Delta l n H_{i, t} \\
\text { (2) }\end{array}$ & $\begin{array}{c}\Delta \ln (Z / H)_{i, t} \\
\text { (3) }\end{array}$ \\
\hline$\beta_{X, \tau}^{E, 0}$ & $\begin{array}{c}0.136 \\
(0.1457)\end{array}$ & $\begin{array}{c}0.219 \\
(0.113)\end{array}$ & $\begin{array}{c}-0.084 \\
(0.1078)\end{array}$ \\
\hline$\beta_{X, \tau}^{R, 0}$ & $\begin{array}{c}-0.033 \\
(0.0802)\end{array}$ & $\begin{array}{c}-0.033 \\
(0.0632)\end{array}$ & $\begin{array}{c}0.004 \\
(0.0576)\end{array}$ \\
\hline$\beta_{X, \rho}^{E, 0}$ & $\begin{array}{c}-0.397 \\
(0.2089)\end{array}$ & $\begin{array}{c}-0.289 \\
(0.1533)\end{array}$ & $\begin{array}{c}-0.109 \\
(0.1564)\end{array}$ \\
\hline$\beta_{X, \rho}^{R, 0}$ & $\begin{array}{c}-1.213^{*} \\
(0.1622)\end{array}$ & $\begin{array}{c}-0.324^{*} \\
(0.1159)\end{array}$ & $\begin{array}{l}-0.891^{*} \\
(0.124)\end{array}$ \\
\hline$\beta_{X, \tau}^{E, 1}(\mathrm{Lag})$ & $\begin{array}{c}0.04 \\
(0.1366)\end{array}$ & $\begin{array}{c}0.283^{*} \\
(0.1075)\end{array}$ & $\begin{array}{c}-0.243^{*} \\
(0.1003)\end{array}$ \\
\hline$\beta_{X, \tau}^{R, 1}$ (Lag) & $\begin{array}{c}0.071 \\
(0.090)\end{array}$ & $\begin{array}{c}0.027 \\
(0.0694)\end{array}$ & $\begin{array}{c}0.042 \\
(0.0643)\end{array}$ \\
\hline$\beta_{X, \rho}^{E, 1}(\mathrm{Lag})$ & $\begin{array}{c}0.028 \\
(0.189)\end{array}$ & $\begin{array}{l}-0.189 \\
(0.139)\end{array}$ & $\begin{array}{c}0.2 \\
(0.1429)\end{array}$ \\
\hline$\beta_{X, \rho}^{R, 1}(\mathrm{Lag})$ & $\begin{array}{c}-0.608^{*} \\
(0.1721)\end{array}$ & $\begin{array}{c}-0.365^{*} \\
(0.1242)\end{array}$ & $\begin{array}{c}-0.226 \\
(0.131)\end{array}$ \\
\hline No. of Observations & & $1,696,20$ & \\
\hline
\end{tabular}

Notes: "Signifies a statistically significant difference from $0 .{ }^{\dagger}$ Signifies a statistically significant difference from -1 (for coefficients on contemporaneous net-of-average tax rates (1- $\rho$ ) only). Results are for quintic specification only. 
Table B2. Estimated coefficient for regressions of $\Delta \ln Z_{i, t}, \Delta \ln H_{i, t}$ and $\Delta \ln (Z / H)_{i, t}$, separate employee and employer NICs rates, and including changes in NICs rates lagged one period

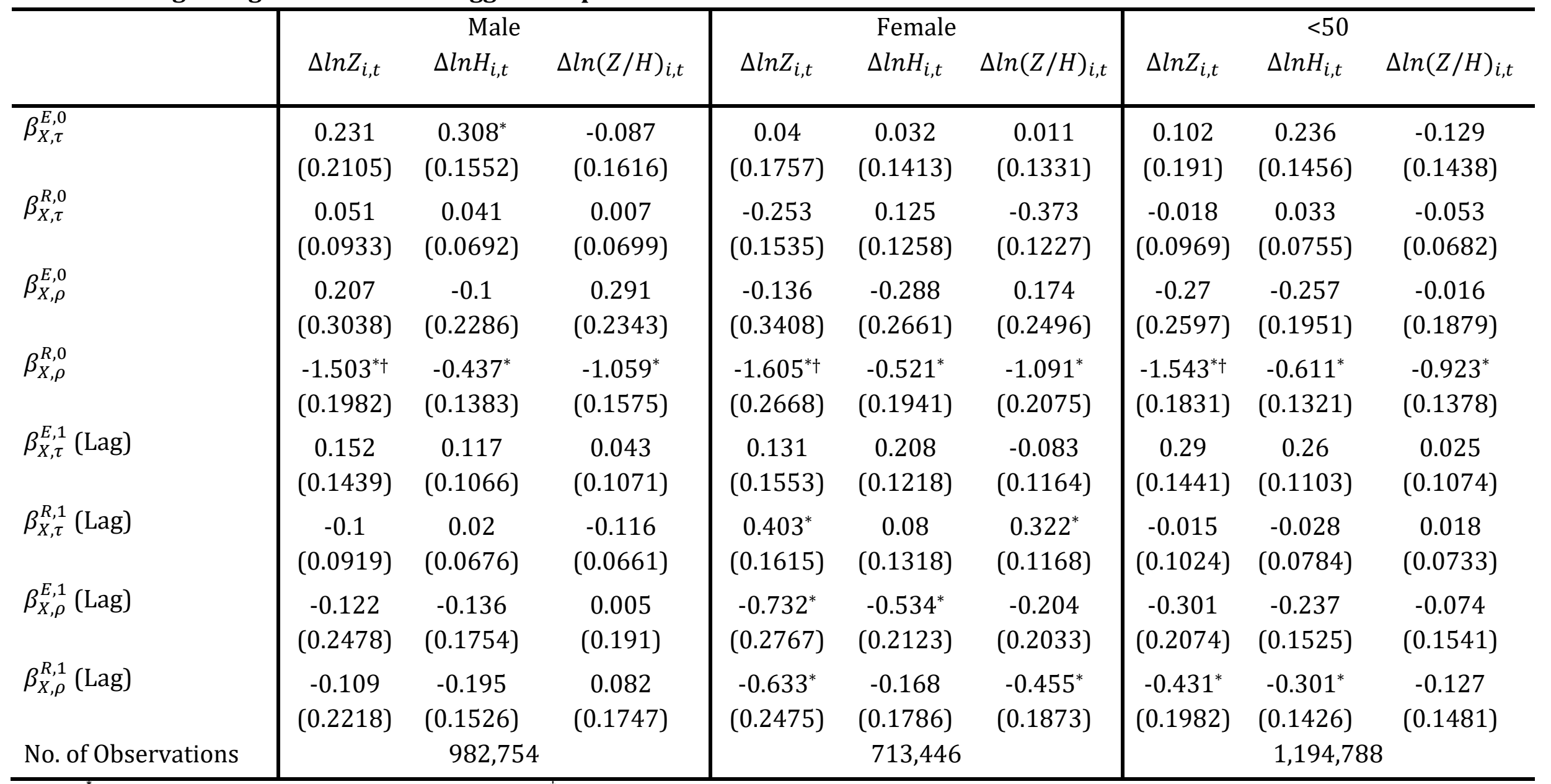

\footnotetext{
Notes: "Signifies a statistically significant difference from $0 .{ }^{\dagger}$ Signifies a statistically significant difference from -1 (for coefficients on contemporaneous net-of-average tax
} rates $(1-\rho)$ only). Results are for quintic specification only. 
Table B2 (continued). Estimated coefficient for regressions of $\Delta \ln Z_{i, t}, \Delta \ln H_{i, t}$ and $\Delta \ln (Z / H)_{i, t}$, separate employee and employer NICs rates, and including changes in NICs rates lagged one period

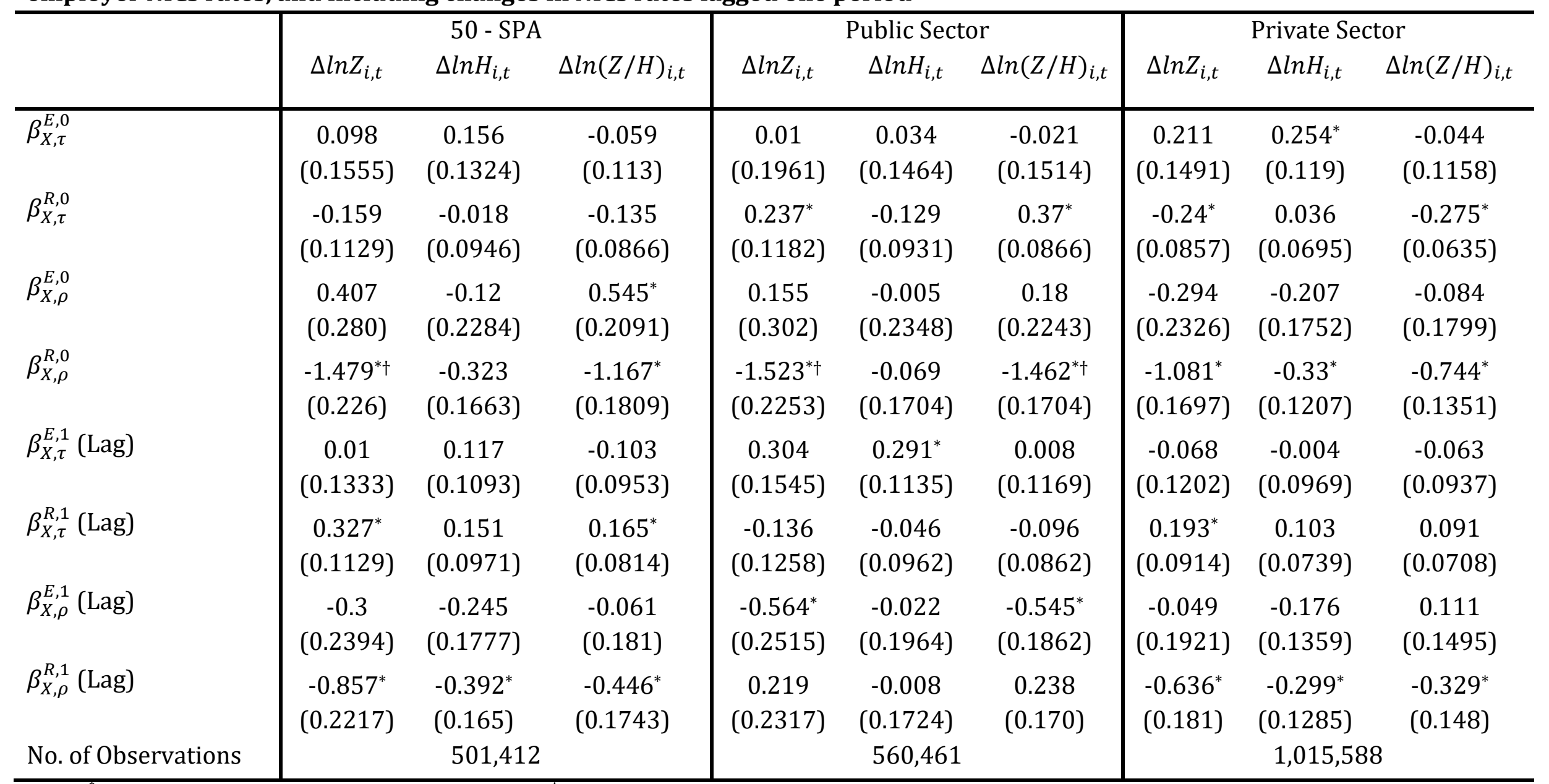

\footnotetext{
Notes: "Signifies a statistically significant difference from $0 .{ }^{\dagger}$ Signifies a statistically significant difference from -1 (for coefficients on contemporaneous net-of-average tax
} rates (1- $\rho$ ) only). Results are for quintic specification only. 